Distributiol

\title{
INTERACTIONS OF STRUCTURALLY MODIFIED SURFACTANTS WITH RESER VOIR MINERALS: CALORIMETRIC, SPECTROSCOPIC AND ELECTROKINETIC STUDY
}

Final Report

By

P. Somasundaran

A. Sivakumar

Q. Xu

March 1991

Work Performed Under Contract No. FG22-89BC14432

Prepared for

U.S. Department of Energy

Assistant Secretary for Fossil Enersy

Jerry Casteel, Project Manager

Bartlesville Project Office

P.O. BO. 1.398

Barflesville, ()K 740015

\section{Prepared by}

Columbia University

School of Engineering and $A$ pplied Science

New York, New York 10027

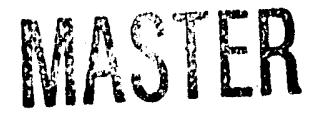




\section{TABLE OF CONTENTS}

EXPERIMENTAL

Materials

Experimental Conditions

Methods

Adsorption of alkyl xylene sulfonates

Enthalpy of micellization of pure components

Enthalpy of adsorption

Electrokinetic potential of alumina

Excess enthalpy of mixing

Adsorption of surfactant mixtures on kaolinite 


\section{SUMMARY}

The goal of this project was to develop an understanding of the adsorption of structurally modified surfactants and their interactions in the bulk and at the solid/liquid interface. A multi-pronged approach consisting of surface tensiometry, adsorption determination, microcalorimetry and electrokinetics measurement was used in this project to elucidate the effect of surfactant structure, specifically the effect of the position of sulfonate and methyl groups on the aromatic ring of alkyl xylene sulfonates on their adsorption. The study revealed that small changes in the position of the above functional groups have marked effect on their adsorption behavior; particularly the position of sulfonate relative to the methyl groups was found to play an important role. Microcalorimetric studies showed that heminicellization of the surfactants was entropy driven and that the difference in the adsorption of the surfactants was due to differences in the steric hindrance to the packing of the molecules in the aggregates. The electrokinetic effects of the surfactants was investigared by measuring changes in the zeta potential of the mineral due to the surfactant adsorption and the studies indicated that the charge charateristics of the surfactants were not affected by the change in the position of the functional groups.

Adsorption of anionic/nonionic and cationic/nonionic surfactant mixtures on a complex mineral, kaolinite was also investigated. Synergism was observed for both the systems and was attributed to increased chain-chain interaction and formation of mixed surfactant clusters. In the pre-micellar region, adsorption of the anionic and the nonionic surfactant increased in the presence of each other, but above the $\mathrm{CMC}$, the adsorption of the anionic surfactant decreased while that of the nonionic increased. Most interestingly, the adsorption of the nonionic surfactant in the plateau region showed a maximum at the equimolar ratio of the surfactants. These results are explained in terms of decreased monomer concentrations and the 
structure of the surfactants in the cluster. The similarity of the interactions between the species in the anionic/monionic and cationic/nonionic mixtures indicated that hydrophobic association of the hydrocarbon tails was the main mechanism of the observed synergism.

\section{OBJECTIVE}

The objective of this project is to elucidate mechanisms of adsorption of structurally modified surfactants on reservoir minerals and to develop a full understanding of the effect of the surfactant structure on the nature of the adsorbed layers at the molecular level. An additional aim is to study the adsorption of surfactant mixtures on simple well-characterized minerals and on complex minerals representing real conditions. The practical goal of these studies is the identification of the optimum surfactant structures and their combinations for micellar flooding.

\section{INTRODUCTION}

Adsorption of surfactants on reservoir minerals reduces the efficiency of micellar flooding process and represents an economic loss. The key to increasing the efficiency lies in the identification of optimum parameters and conditions that will minimize the loss through adsorption. Among the different parameters that influence surfactant adsorption, surfactant structure plays a major role for most of the reservoir systems (1-4). In addition, it is to be noted that surfactants used in chemical flooding processes are invariably mixtures of surfactants of different structures. Hence, it is important to delineate the mechanisms of the effect of structure on the interfacial behavior of surfactants and of the interactions between various types of surfactants. For this, there is first a need to prepare isomerically pure surfactants since, impurities even in very small amounts can mask the effect of 
the structural variations (5). Similarly, sinee mixtures do not generally hehave like single surfactants, there is a need to conduct studies with well defined surfactant mixtures of pure surfactants in order to reliably model the behavior in actual systems (6-14). In this work, the experiments on adsorption were focussed on the position of sulfonate and methyl groups on the aromatic ring of alky! xylene sulfonates. A multi-pronged approach consisting of calorimetry, electrokinetics. wettability and spectroscopy is planned to elucidate the adsorption mechanism of surfactants and their mixtures on minerals such as alumina and kaolinite.

\section{EXPERIMEN'TAL}

Materials:

Surfactants: 4C11 124 metaxylene sulfonate (124MXS), 4C11 135 metaxylene sulfonate (135MXS) and 4C11 125 paraxylene sulfonate (125PXS) used were obtained from ARCO Exploration and Technology Company. The surfactants, specified to be at least $97 \%$ isomerically pure, were used as received. Their structures are given below:

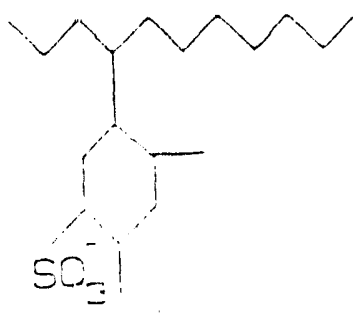

$124 \mathrm{MXS}$

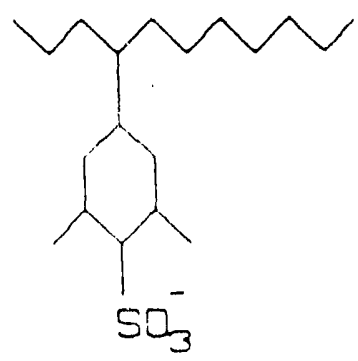

$135 \mathrm{MXS}$

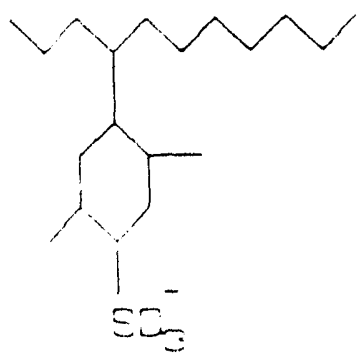

$125 \mathrm{P} \times \mathrm{S}$ 
Dodecylsulfate purchased from Fluka Chemicals and dodecyltrimethylammonium chloride from Tokyo Kasai Chemicals were specified to be $99 \%$ pure and was used as received. Octaethylene glycol n-dodecyl ether $\left(\mathrm{C}_{12} \mathrm{EO}_{8} \mathrm{OH}\right)$ purchased from Nikko Chemicals was specified to be $98 \%$ pure and was used as received.

Alumina: High purity Linde A alumina purchased from Union Carbide was used. Alumina was chosen as the substrate since it is a weli-characterized mineral and would help in isolating the effect of surfactant structure on adsorption. The specific surface area was determined by nitrogen adsorption to be $15 \mathrm{~m}^{2} / \mathrm{g}$.

Kaolinite: A well crystallized sample of Georgia Kaolinite purchased from the clay repository at the University of Missouri was subjected to an ion-exchange treatment (15) to yield homoionic kaolinite. The surface area determined by nitrogen adsorption was $8.2 \mathrm{~m}^{2} / \mathrm{g}$.

\section{Experimental Conditions:}

All the experiments with metaxylene sulfonates were carried out at $4.3 .3^{\circ} \mathrm{C}$ (1) permit their dissotion and at a constant ionic strength of $3 \times 10^{-2} \mathrm{kmol} / \mathrm{m}^{3} \mathrm{NaCl}$. The adsorption of the anionic/nonionic surfactant mixtures was carried out at $25^{(1)} \mathrm{C}$ and at an ionic strength of $3 \times 10^{-2} \mathrm{kmol} / \mathrm{m}^{3} \mathrm{NaCl}$.

Methods:

Surface Tension: Surface tension was measured using a water-jacketed du Nouy ring tensiometer set to the test temperature.

Adsorption: For adsorption on aluminat, a 1 gram sample was conditioned with $5 \mathrm{ml}$ of (0.)(1). 11 Nald for 2 hours. Then, a $5 \mathrm{ml}$ sample of the surfictant solution of

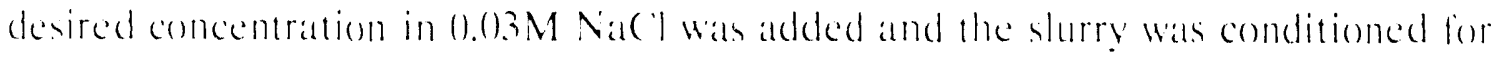


24 hours. The slurry was then centrifuged and the supernatant analyzed for surfactant concentration. In the case of kaolinite, the procedure was the same except that slurry was conditioned for 72 hours instead of 24 hours.

Surfactant Analysis: The anionic surfactants were analyzed by a two phase titration technique (16). The nonionic surfactant was analyzed using HPLC with refractive index detection. The stationary phase was a $\mathrm{C}_{18}$ bonded silica column and the mobile phase was a 90/10 mixture of acetonitrile and water.

Microcalorimetry: Calorimetric experiments were performed using an L.KB 2107 differential isothermal microcalorimetry system. It consists of a 2107/112 batch microcalorimeter, 2107/210 thermostat air bath, 2107/310 control unit and HewlettPackard 3390 integrator/plotter.

The calorimeter body has a cylindrical shape with a rotation shaft along its axis. It is suspended inside the air bath chamber by its shaft, and is able to rotate to mix samples through a motor and gear system within the chamber. Within the calorimeter body are two 18 carat gold vessels, one for sample solutions and the other for reference. Each vessel is partitioned into volumes of $2 \mathrm{~cm}^{3}$ and $4 \mathrm{~cm}^{3}$, each of which has an opening capped by a teflon stopper. The four compartments are filled with reactant, reference solution and diluent.

Each vessel is in thermal contact with a pair of thermopiles and a heat sink assembly. Small temperature changes caused by reactions in each vessel after mixing, result in heat exchange between the vessel and its heat sink. As a consequence, heal flows across the thermopiles, causing a proportional electromotive foree to be generated. The outputs of the themopiles associated with cach vessel are connected in opposition to one another, so that any electromotive force common to both vessels is nullified. The resulting output voltage is thus a 
measure of the reaction heat alone. This signal is amplified and passed on to a digital read-out system and integrator/printer. A calibration heater is built into each vessel, and a temperature sensor and auxiliary heater are located between the two vessels. Temperature stability is $\pm 0.03{ }^{\circ} \mathrm{C}$ and sensitivity is $0.068 \mu \mathrm{W} / \mathrm{V}$ for both detector (thermopile) systems.

The temperature setting of the air bath is $44^{\circ} \mathrm{C}$. Due to heat loss to the surroundings, however, at this setting the calorimeter temperature is only $43.3 \pm$ $0.1^{\circ} \mathrm{C}$. Small daily variations are due to changes in the ambient temperature. Thus, there is a very slight deviation in temperature between surface tension and calorimetry experiments. For each measurement, six hours are required for thermal stability to be re-attained after charging the vessels with solution.

Experiments are initiated by rotating the calorimeter block. Each mixing action consists of two complete revolutions, one in each direction, and is repeated for a sufficient number of times to ensure complete mixing. This is ascertained when consistent signals are recorded for succeeding mixing runs. The integrated area of the reaction, $A_{R}$ is computed by summation of the areas, $a_{i}$, due to each of the $n$ mixing actions minus $\mathrm{n}$ times the area, $\mathrm{a}_{\mathrm{m}}$, due to heat effects from rotation of the calorimeter:

$$
A_{r}=\sum_{i=1}^{n} a_{i}-n a_{m}
$$

Area-heat calibration is then carried out by passing a known current for a set period through the calibration heater of either one of the vessels. Three separate measurements in a narrow range around the reaction area are done for each experiment to obtain a calibration curve. The heat values thus obtained are converted to enthalpies through mass balance calculations. 
The accuracy of the calorimeter was tested by measuring the enthalpy change for a system where precise thermodynamic data was available. Since $\mathrm{NaCl}$ is the electrolyte used in all experiments, its enthalpy of dilution in aqueous solution is suitable for this purpose. The results are shown below in table 1. The mean error is about $3 \%$, thus there is good agreement between measured and literature values (17).

Table 1. Calibration of microcalorimeter with $\mathrm{NaCl}$ solution dilutions at $25^{\circ} \mathrm{C}$. Concentr tions in $\mathrm{mol} / \mathrm{kg}$ and enthalpy values in $\mathrm{cal} / \mathrm{mol}$.

$\begin{array}{llcc}\mathrm{C}_{\mathrm{i}} & \mathrm{C}_{\mathrm{f}} & \Delta \mathrm{H}_{\text {dil }} & \Delta \mathrm{H}_{\text {dil }} \\ \text { (meas) } & \text { (lit) } \\ 0.31 & 0.16 & 7.64 & 7.42 \\ 0.4 & 0.2 & 16.2 & 16.9 . \\ 0.495 & 0.25 & 26.7 & 27.5\end{array}$

\section{RESULTS AND DISCUSSION}

\section{Adsorption of alkylxylene sulfonates}

The adsorption isotherms obtained for the three surfactants on alumina are given in fig. 1. The shape of the isotherms is typical of that of ionic surfactant adsorption on oppositely charged oxide minerals. Following the initial adsorption by electrostatic attraction, the adsorption proceeds through the formation of aggregates known as hemimicelles. The adsorption of 135MXS and 125PXS is higher than that of $124 \mathrm{MXS}$ in the premicellar region but have the same plateau adsorption values. The lower adsorption of $124 \mathrm{MXS}$ could possibly be due to its lower hydrophobicity and to the increased steric constraints to the packing of the surfactant molecules in hemimicelles arising from the position of the sulfonate being 


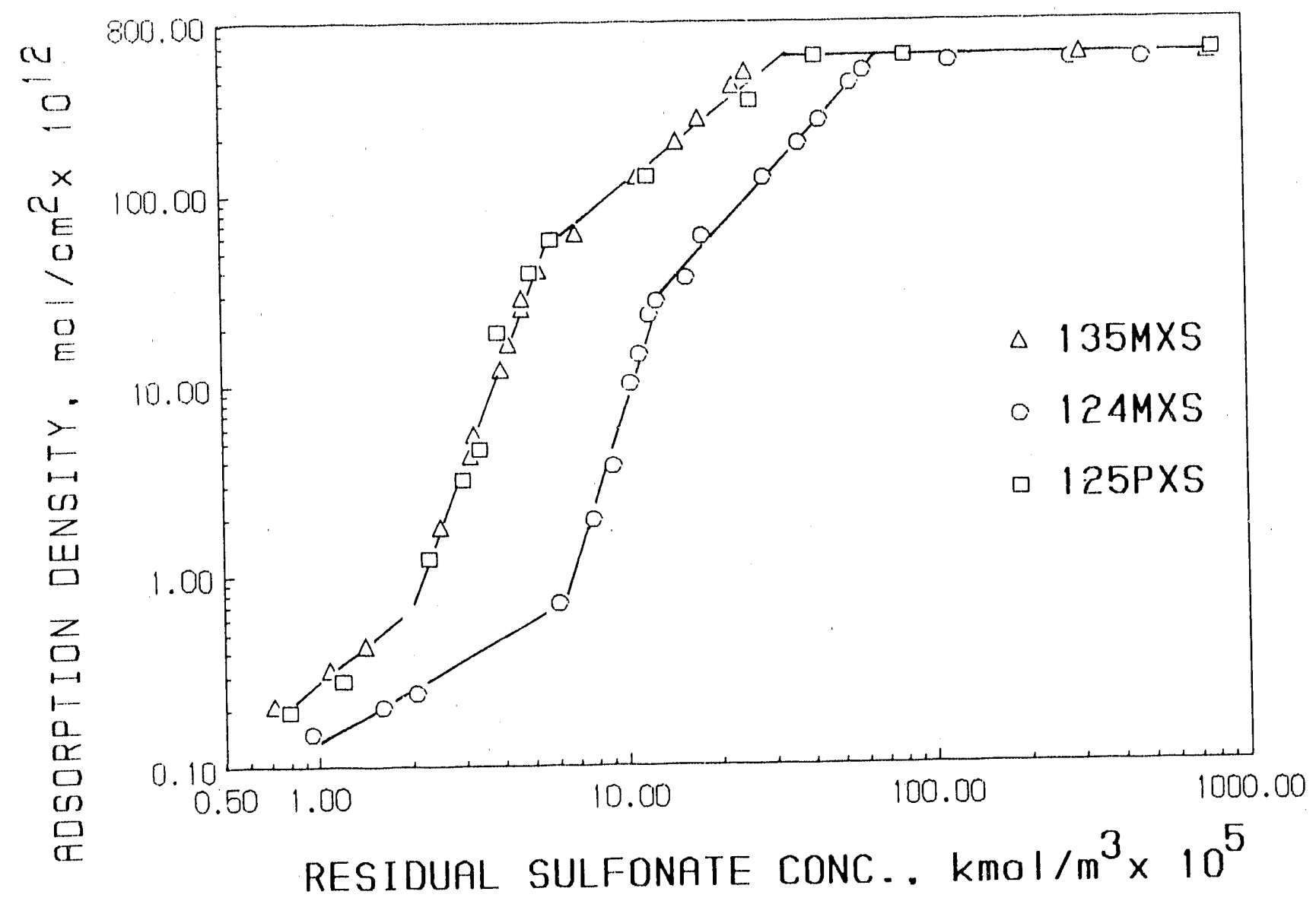

Figure 1.

Adsorption of 124 metaxylene sulfonate, 135 metaxylene sulfonate and 125 paraxylene sulfonate on alumina. 
closer to the main alkyl chain. The same adsorptive behavior of 135MXS and 125PXS seems to indicate that the position of sulfonate is more important than the position of the methyl groups. The reason for the lower adsorption of 124MXS before the formation of hemimicelles is not clear at this point and is discussed later (section on electrokinetic potential of alumina). Reverse phase high performance liquid chromatography was used to get a measure of the relative hydrophobicity of 124MXS and 135MXS. The stationary phase used was a $75 / 25$ mixture of acetonitrile and tetrabutylammoniumphosphate. The retention times of the two surfactants are shown below.

Surfactants

$124 \mathrm{MXS}$

$135 \mathrm{MXS}$
Retention time (min)

7

8.2

The higher retention time of 135MXS shows that it is indeed more hydrophobic than 124MXS.

Surface tension data is useful for interpreting the data for adsorption on solids, since it provides complementary information on the adsorption at the liquid/air interface and also information on surfactant interactions in solution Surface tension was also used to determine the critical micelle concentration (CMC) of the surfactants. The surface tension results obtained for the three surfactants are given in fig. 2. An absence of minimum in the curves indicates that the suriactants are pure. From the figure, it can be seen that 135MXS is more surface active than the 124MXS and 125PXS. Also, the CMC of $124 \mathrm{MXS}\left(6.3 \times 10^{-4} \mathrm{M}\right)$ and $125 \mathrm{PXS}$ $\left(5.3 \times 10^{-4} \mathrm{M}\right)$ is higher than that of $135 \mathrm{MXS}\left(3.3 \times 10^{-4} \mathrm{M}\right)$. It is to be noted that the surface tension of 125PXS is higher than that of $135 \mathrm{MXS}$ indicating lower surface activity, although the adsorption of the two surfactant. vere the same. This indicates that the steric hindrance to the packing of molecules in the adsorbed layer 


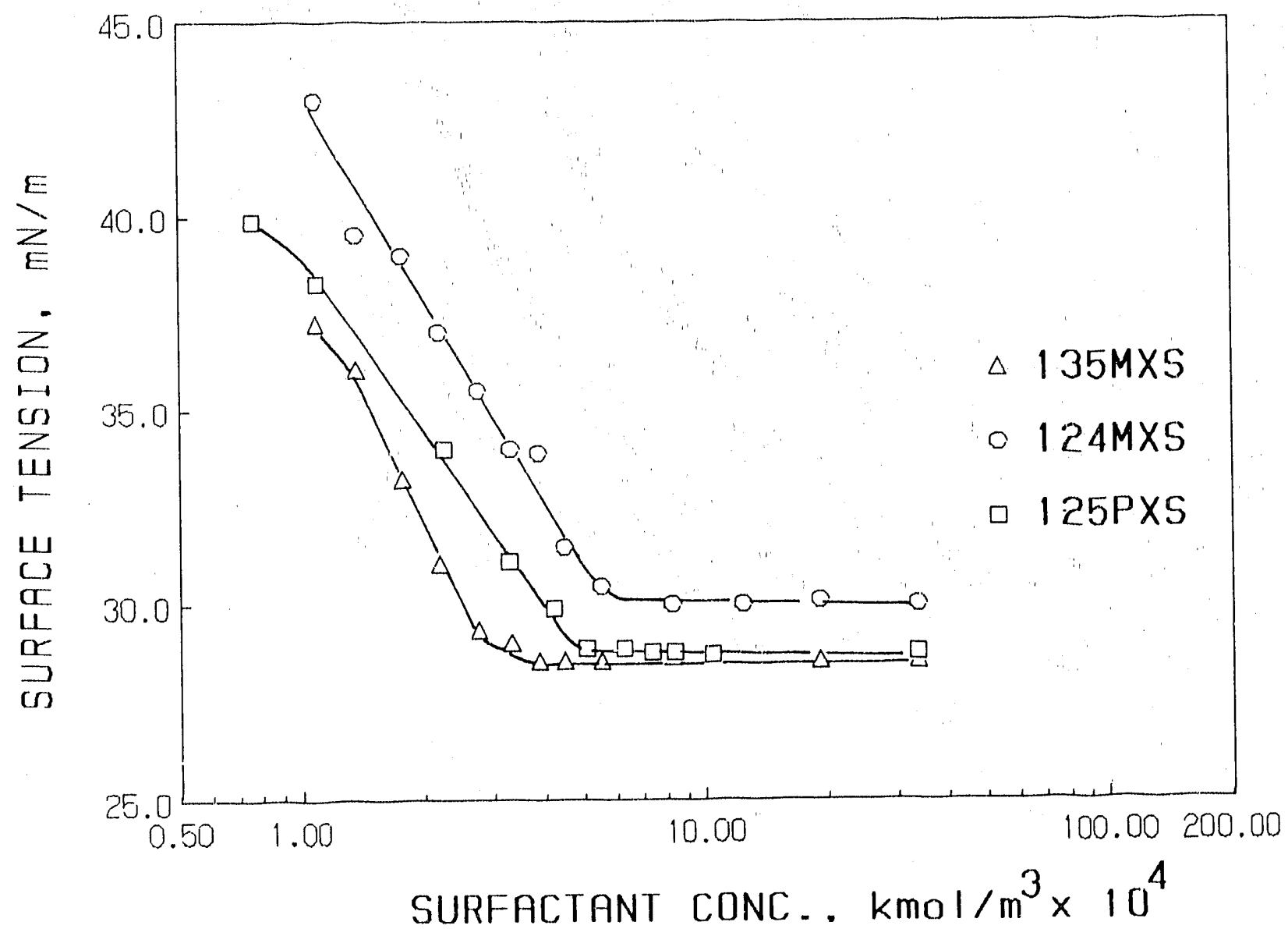

Figure 2.

Surface tension of 124 metaxylene sulfonate, 135 metaxylu,le sulfonate and 125 paraxylene sulfonate solutions. 


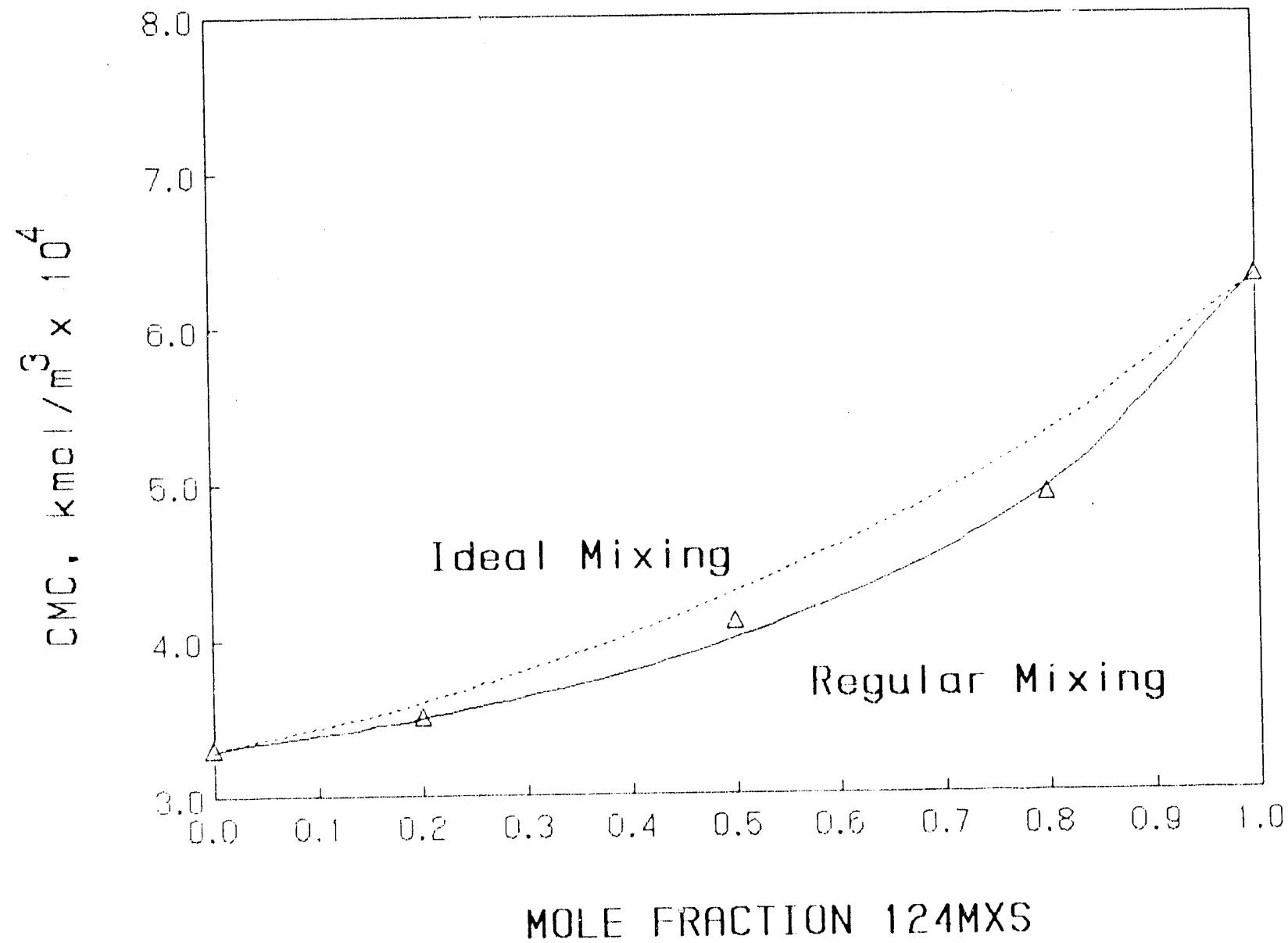

Figure 3.

CMC of 124 metaxylene sulfonate and 135 metaxylene sulfonate mixtures. 
is the main reason for the difference between the adsorption of 124MXS and that of the other two surfactants.

Surface tension was also used to measure the CMC's of the mixtures of 124MXS and $135 \mathrm{MXS}$ and the esults are given in fig. 3. Also, the theoretical CMC values for the different mixtures calculated using the ideal solution and regular solution theories $(10,11)$ are shown in this figure. The equations used to calculate mixed CMC and monomer concentrations above $\mathrm{CMC}$ using the ideal and regular solution theories are derived in Appendix B and $C$ respectively (Appendix A has the list of symbols used in the derivation). The system shows a negative deviation from the ideal behavior which is not normally expected for mixtures of similar surfactants. Regular solution theory fits the data well with an interaction parameter $(\beta)$ of -0.32 . The deviations from ideality can be attributed to the difficulty in packing of the molecules in the mixed micelles.

\section{Enthalpy of Micellization of Pure Components}

\section{5 metaxylene sulfonate}

Heat of dilution data for premicellar and micellar 135MXS solutions are given in tables 2 and 3 , respectively.

Table 2: Heat of dilution of premicellar solutions at $43.3^{\circ} \mathrm{C}$ and $3 \times 10^{-2} \mathrm{kmol} / \mathrm{m}^{3}$ $\mathrm{NaCl}$. Concentrations are in $\mathrm{kmol} / \mathrm{m}^{3}$ and enthalpies in cal $/ \mathrm{mol}$.

$\begin{array}{llr}\mathrm{C}_{\mathrm{i}} & \mathrm{C}_{\mathrm{f}} & \Delta \mathbf{H}_{\text {dil }} \\ 3.11 \times 10^{-4} & 2.02 \times 10^{-4} & -120 \\ 3.11 \times 10^{-4} & 2.56 \times 10^{-4} & -116 \\ 3.11 \times 10^{-4} & 2.1 \times 10^{-4} & -118\end{array}$


Table 3: Heat of dilution micellar solutions at $43.3^{\circ} \mathrm{C}$ and $3 \times 10^{-2} \mathrm{kmol} / \mathrm{m}^{3} \mathrm{NaCl}$. Concentrations are in $\mathrm{kmol} / \mathrm{m}^{3}$, heats in cal and enthalpies in cal $/ \mathrm{mol}$.

$\mathrm{C}_{\mathrm{i}}$

$5.77 \times 10^{-4}$

$8.92 \times 10^{-4}$

$1.126 \times 10^{-4}$
$\mathrm{C}_{\mathrm{f}}$

$2.8 \times 10^{-4}$

$2.8 \times 10^{-4}$

$2.58 \times 10^{-4}$
$Q_{\text {dil }}$

$3.93 \times 10^{-4}$

$5.44 \times 10^{-4}$

$4.87 \times 10^{-4}$ $\wedge \mathrm{H}_{\mathrm{m}}$

$-1041$

$-1084$

$-1148$

The dilution of premicellar solutions results in an exothermic change of -118 $\mathrm{cal} / \mathrm{mol}$, and is due to dilution of sulfonate monomers. For the dilution of micellar solutions, demicellization accounts for the bulk of the heat change, which for $135 \mathrm{MXS}$ is endothermic. In addition to demicellization, dilution of micellar solutions will result in dilution of micelles if the final concentration is above the CMC, or dilution of monomers if it is below CMC.

For the purpose of calculating the enthalpy of micellization, experiments were designed so that correction for dilution of micelles was not required, i.e. micellar solutions were diluted to below the corresponding critical micelle consentrations. The values obtained in this manner (column 3 of Table 3 ) were then corrected for monomer dilution using the value of $-118 \mathrm{cal} / \mathrm{mol}$ from Table 2 . and assuming pseudo-phase separation at a $\mathrm{CMC}$ of $3.3 \times 10^{-4} \mathrm{kmol} / \mathrm{m}^{3}$. Mathematically, this can be expressed as:

$$
\Delta H_{m}=-\left\{Q_{t} \cdot \wedge H_{s} C_{i} V_{i}\right\} /\left[\left\{C_{i}-C M C\right\} V_{i}\right]
$$


where $\triangle \mathrm{H}_{\mathrm{m}}$ is the enthalpy of micellization, $\Delta \mathrm{H}_{\mathrm{s}}$ the enthalpy of monomer dilution, $Q_{t}$ the total heat change measured, $C_{i}$ the surfactant concentration before dilution, and $\mathrm{V}_{\mathrm{i}}$ the volume of surfactant solution before dilution.

The $\Delta \mathrm{H}_{\mathrm{m}}$ values are given in coiumn 4 of Table 3 and show excellent consistency with a mean value of $-1091 \mathrm{cal} / \mathrm{mol}$. Since the standard state of micelles is defined to be the state of infinite dilution, i.e. CMC, and the dilution measurements are carried out in the region of the CMC, the valu ' of $-1091 \mathrm{cal} / \mathrm{mol}$ is approximately $\triangle \mathrm{H}^{\mathrm{O}}{ }_{\mathrm{m}}$

\section{4 metaxylene sulfonate}

The heat of dilution results for premicellar and micellar 124MXS solutions are given in tables 4 and 5 respectively.

Table 4 Heat of dilution of $124 \mathrm{MXS}$ monomer solutions at $43.3^{\circ} \mathrm{C}$ and $3 \times 10^{-2}$ $\mathrm{kmol} / \mathrm{m}^{3} \mathrm{NaCl}$. Concentrations are in $\mathrm{kmol} / \mathrm{m}^{3}$ and enthalpies in $\mathrm{cal} / \mathrm{mol}$.

$\mathrm{C}_{\mathrm{i}}$

$6.22 \times 10^{-4}$

$6.22 \times 10^{-4}$
$\mathrm{C}_{\mathrm{f}}$

$4.96 \times 10^{-4}$

$4.97 \times 10^{-4}$
$\Delta \mathrm{H}_{\mathrm{dil}}$

$-33$

$-39$ 
Table 5 Heat of dilution of $124 \mathrm{MXS}$ micellar solutions at $43.3^{\circ} \mathrm{C}$ and $3 \times 10^{-2}$ $\mathrm{kmol} / \mathrm{m}^{3} \mathrm{NaCl}$. Concentrations are in $\mathrm{kmol} / \mathrm{m}^{3}$ and enthalpies in cal $/ \mathrm{mol}$.

$\begin{array}{llll}\mathrm{C}_{\mathrm{i}} & \mathrm{C}_{\mathrm{f}} & \mathrm{Q}_{\text {dil }} & \Delta \mathrm{H}_{\mathrm{m}} \\ 9.96 \times 10^{-4} & 5.67 \times 10^{-4} & 4.94 \times 10^{-4} & -745 \\ 9.96 \times 10^{-4} & 5.68 \times 10^{-4} & 4.74 \times 10^{-4} & -720 \\ 1.2 \times 10^{-3} & 6.01 \times 10^{-4} & 9.31 \times 10^{-4} & -858\end{array}$

\section{$-774$}

The mean heat of monomer dilution is $-36 \mathrm{cal} / \mathrm{mol}$, which is significantly smaller than that for $135 \mathrm{MXS}$ dilution. Applying this correction to data obtained with demicellized solutions and using a $\mathrm{CMC}$ of $6.3 \times 10^{-4} \mathrm{kmol} / \mathrm{m}^{3}$ yields a mean $\Delta \mathrm{H}^{0}{ }_{\mathrm{m}}$ of $-774 \mathrm{cal} / \mathrm{mol}$.

\section{5 paraxylene sulfonate}

The heat of dilution results for premicellar and micellar 125PXS solutions are given in tables 6 and 7 respectively.

Table 6 Heat of dilution of premicellar solutions at $43.3^{\circ} \mathrm{C}$ and $3 \times 10^{-2} \mathrm{kmol} / \mathrm{m}^{3}$ $\mathrm{NaCl}$. Concentrations are in $\mathrm{kmol} / \mathrm{m}^{3}$ and enthalpies in $\mathrm{cal} / \mathrm{mol}$.<smiles>[SiH3]</smiles>

$2.86 \times 10^{-4}$

$2.86 \times 10^{-4}$

$3.98 \times 10^{-4}$

$3.98 \times 10^{-4}$
$\mathrm{C}_{\mathrm{f}}$

$1.43 \times 10^{-4}$

$1.42 \times 10^{-4}$

$1.98 \times 10^{-4}$

$200 \times 10^{-4}$ $\triangle \mathrm{H}_{\mathrm{dil}}$

$-363$

$-348$

$-365$

$-344$ 
Table 7 Heat of dilution micellar solutions at $43.3^{\circ} \mathrm{C}$ and $3 \times 10^{-2} \mathrm{kmol} / \mathrm{m}^{3} \mathrm{NaCl}$. Concentrations are in $\mathrm{kmol} / \mathrm{m}^{3}$, heats in cal and enthalpies in cal $/ \mathrm{mol}$.

$\mathrm{C}_{\mathrm{i}}$

$1.06 \times 10^{-3}$

$1.06 \times 10^{-3}$

$8.52 \times 10^{-4}$
$\mathrm{C}_{\mathrm{f}}$

$5.2 \times 10^{-4}$

$5.1 \times 10^{-4}$

$4.3 \times 10^{-4}$
$Q_{\text {dil }}$

$5.3 \times 10^{-4}$

$5.0 \times 10^{-4}$

$4.96 \times 10^{-4}$ $\wedge \mathrm{H}_{\mathrm{m}}$

$-1652$

$-1677$

$-1685$

The mean heat of monomer dilution is $-354 \mathrm{cal} / \mathrm{mol}$, which is higher than that for 135MXS dilution. Applying this correction to data obtained with demicellized solutions and using a CMC of $5.3 \times 10^{-4} \mathrm{kmol} / \mathrm{m}^{3}$ yields a mean $\Delta \mathrm{H}^{\mathrm{O}}{ }_{\mathrm{m}}$ of $\quad-1671$ $\mathrm{cal} / \mathrm{mol}$.

The standard free energy of micellization according to the phase separation model (18) is given by

$\triangle \mathrm{G}^{\mathrm{O}}=2 \mathrm{RT} \ln (\mathrm{CMC})$

where $\mathrm{CMC}$ is the critical micelle concentration expressed as a mole fraction.

The standard entropy of micellization is then calculated from the following equation $\Delta \mathrm{S}^{\mathrm{O}}=\left(\Delta \mathrm{H}^{\mathrm{O}}-\Delta \mathrm{G}^{\mathrm{O}}\right) / \mathrm{T}$

The values of the thermodynamic parameters of micellization for the two surfactants are tabulated below:

$\begin{array}{cccc} & \Delta \mathrm{H}^{\circ} & \Delta \mathrm{G}^{\mathrm{O}} & \wedge \mathrm{S}^{\circ} \\ & (\mathrm{cal} / \mathrm{mol}) & (\mathrm{cal} / \mathrm{mol}) & (\text { cal } / \text { deg.mol }) \\ 135 \mathrm{MXS} & -1091 & -15,226 & 45 \\ 124 \mathrm{MXS} & -774 & -14,407 & 43 \\ 125 \mathrm{PXS} & -1671 & -14,626 & 41\end{array}$


The main contribution to the free energy change of micellization comes from the entropy change arising from the removal of water molecules from around the hydrocarbon chain.

\section{Enthalpy of Adsorption of AlkylXylene Sulfonates}

The differential adsorption enthalpy of the thrce surfactants as a function of the adsorption density is shown in figure 4. The enthalpy of adsorption of the surfactants is exothermic at all adsorption densities and decreases rapidly with the formation of surfactant aggregates through hemimicellization. This indicates that like the formation of micelles, the formation of hemimicelles is also entropy driven. The enthalpy of adsorption of the 135MXS and 125PXS is higher than that of the $124 \mathrm{MXS}$ at low adsorption densities indicating greater attraction to the mineral which results in its higher adsorption in region I as seen from figure 1. This greater attraction to the mineral could be due to $135 \mathrm{MXS}$ and 125PXS being more negatively charged than $124 \mathrm{MXS}$, since the sulfonate is in the para position. This was tested by measuring the electrokinetic potential after adsorption of the three surfactants and this will be discussed later. Once hemimicelles form, the enthalpy of adsorption of the surfactants is same. The free energy of hemimicellization of $135 \mathrm{MXS}$ and 125PXS is higher than that of 124MXS as is evident from their greater adsorption. Since, the enthalpy of hemimicellization is the same, the entropy of hemimicellization is higher for the 135MXS and 125PXS wan for 124MXS. The entropy can be considered to result from two contributions: a negative contribution due to the ordering of the surfactant in the aggregate and a positive and major contribution from the release of the water molecules structured around the hydrocarbon tail upon its association. The tighter the packing of the molecules in 


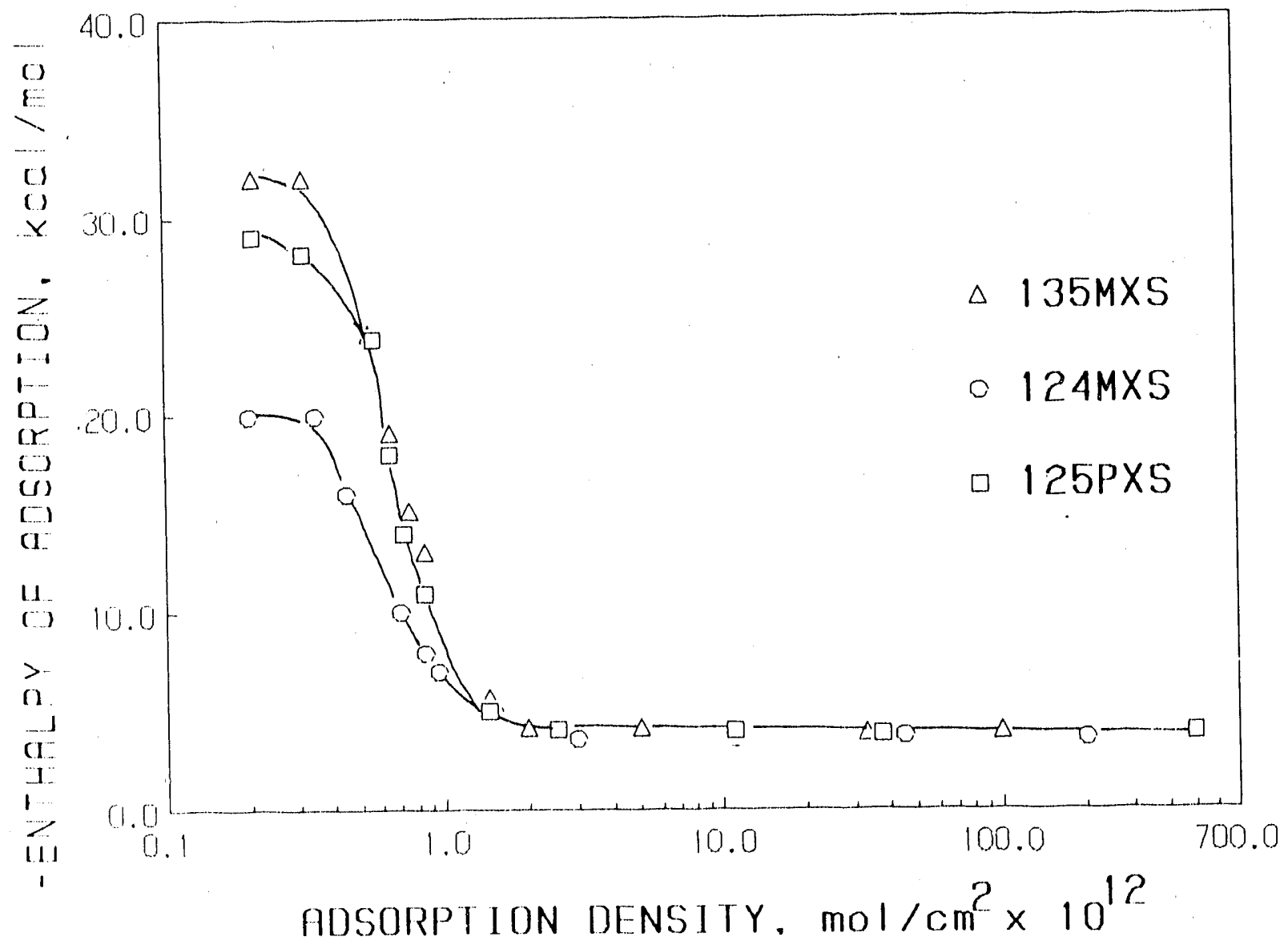

rigure 4.

Differential adsorption enthalpies of 124 metaxyiene sulfonate, 135 metaxylene sulfonate and 125 paraxylene sulfonate. 
the aggregates, more will be the release of the water molecules and higher will be the entropy. Thus, the higher entropy of hemimicellization could indicate a tighter packing of the molecules which was the initial speculation of the higher adsorption.

\section{Electrokinetic Potential of Alumina}

The zeta potential of alumina after the adsorption of the three surfactants as a function of the adsorption density is shown in figure 5. The zeta potential is the same for the three surfactants at all the adsorption densities studied. This indicates that the charge characteristics of the surfactants are the same or that the technique is not sensitive to such small changes in the charge of the surfactant. This does not explain the greater attraction of $135 \mathrm{MXS}$ and 125PXS to the mineral at low concentrations. One possible reason could be that the water molecules near the alumina surface being structured are relatively less hydrophilic (19) and 124MXS due to its lower hydrophobicity (as measured by HPLC) is drawn lesser to the interface than the other two surfactants.

\section{Excess Enthalpy of Mixing of 124MXS and 135MXS}

The mixed micellization of 124MXS and 135MXS showed negative deviations from ideal mixing that regular solution theroy adequately fit the mixed CMC data. However, it has been shown that in certain systems, the thermodynamic assumptions of the regular solution theory are not valid even though it fits the data well (20). Therefore it is important to verify the validity of the assumptions prior to using the theory. Microcalorimetry was used to measure the heats of mixed micclle formation of $124 \mathrm{MXS}$ and $135 \mathrm{MXS}$. The technique actually involves measuring the excess heat of mixed micellization relative to the pure component micelles by mixing equimolar concentrations of the two pure micellar solutions (21). Surfactant 


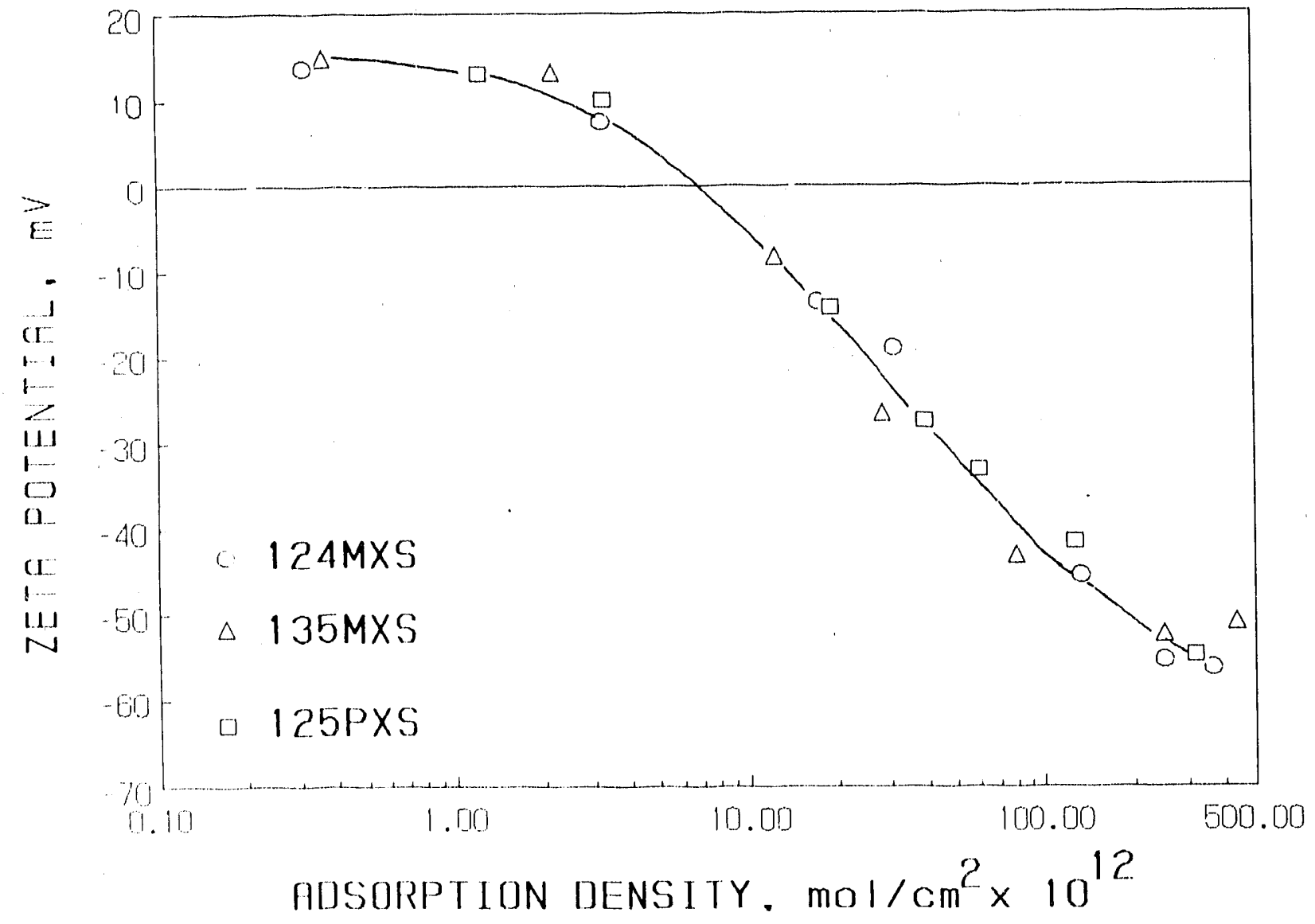

Figure $5 . \quad$ Zeta potential of alumina after surfactant adsorption. 
composition is varied by changing the relative volumes of the two solutions. Only solutions at concentrations that are at least 50 times the mixed "MC were used to ensure that the actual mixed micelle composition differed little from the total surfactant composition. By plotting reaction heat as a function of concentration, it is possible to eliminate monomer dilution contributions, as the excess enthalpy of mixing can be directly obtained from the slope. This is illustrated in figure 6 which shows the excess heat curves for two surfactant compositions. The extent of monomer contributions can be quantified by extrapolating the curves to the y-axis.

Excess enthalpy curves have been obtained at various surfactant compositions and the results are plotted in figure 7. The fact that the enthalpy of mixing is non-zero at all compositions suggests that the mixtures are non ideal. An interaction parameter $(\beta)$ of -0.21 fits the calorimetric data well and it compares well with $\beta$ of -0.32 obtained from the surface tension data. This indicates that the assumption of the regular solution theory (excess entropy of mixing is zero) is valid for the system of $124 \mathrm{MXS}$ and $135 \mathrm{MXS}$.

\section{Adsorption of surfactant mixtures on kaolinite}

\section{Adsorption from single surfactant solutions}

Isotherms for the adsorption of anionic sodium dodecylsulfate and cationic dodecyltrimethylammonium chloride are shown in figure 8 , while that of the nonionic octaethyleneglycol mono-n-dodecyl ether is given in figure 9. It can be seen from figure 8 that both the anionic $\mathrm{C}_{12} \mathrm{SO}_{4} \mathrm{Na}$ and the cationic $\mathrm{C}_{12}\left(\mathrm{CH}_{3}\right)_{3} \mathrm{NCl}$ adsorb on kaolinite at the same pH value. This is consistent with an electrostatic adsorption mechanism for this system since both positive and negative sites coexist on kaolinite surface $(15,22)$. The above adsorption mechanism is also supported by 


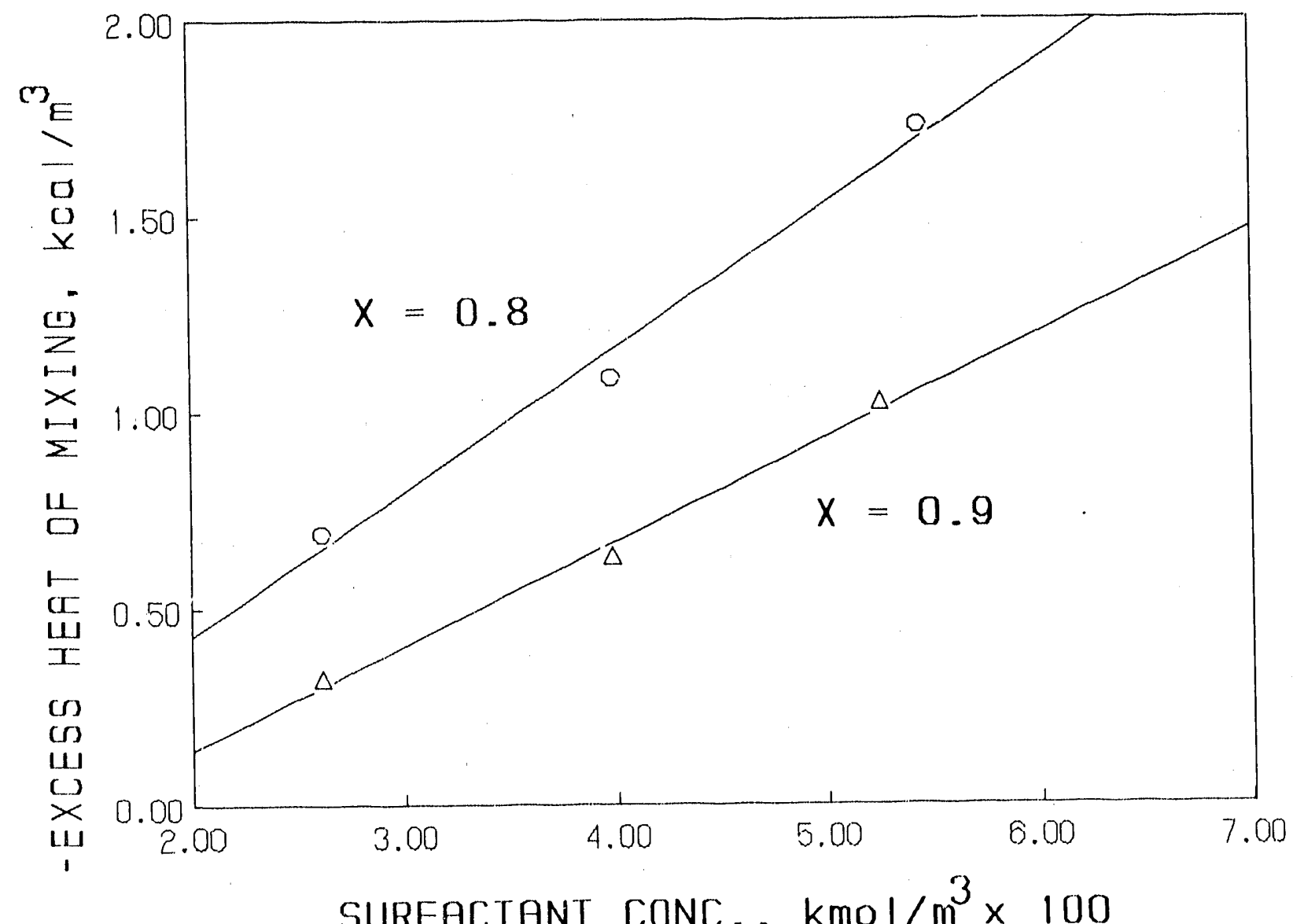

Figure 6. Excess heat of mixing of 124 metaxylene sulfonate and 135 metaxylene sulfonate. 


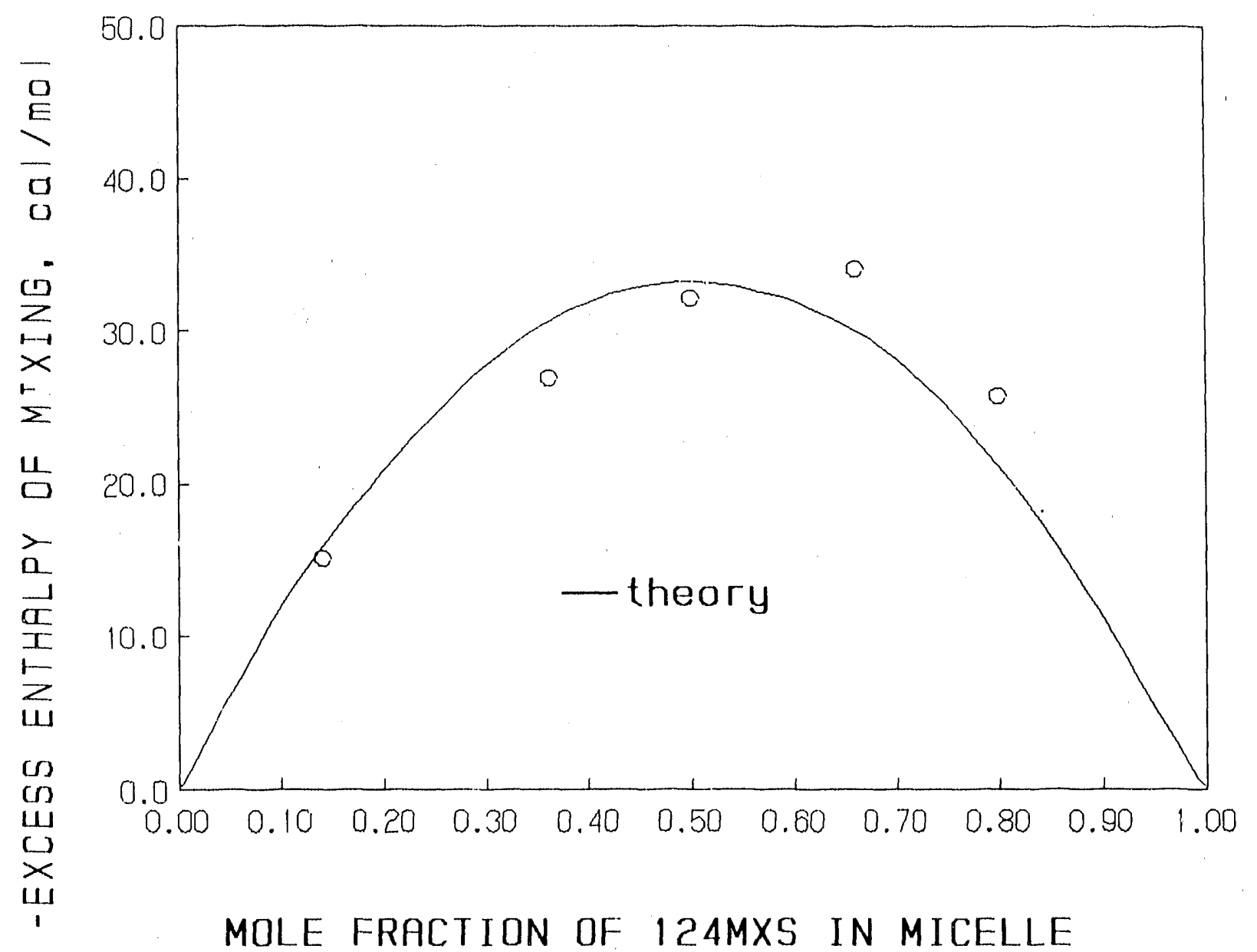

Figure 7. Excess enthalpy of formation of mixed micelles of 124 metaxylene sulfonate and 135 metaxylene sulfonate. 


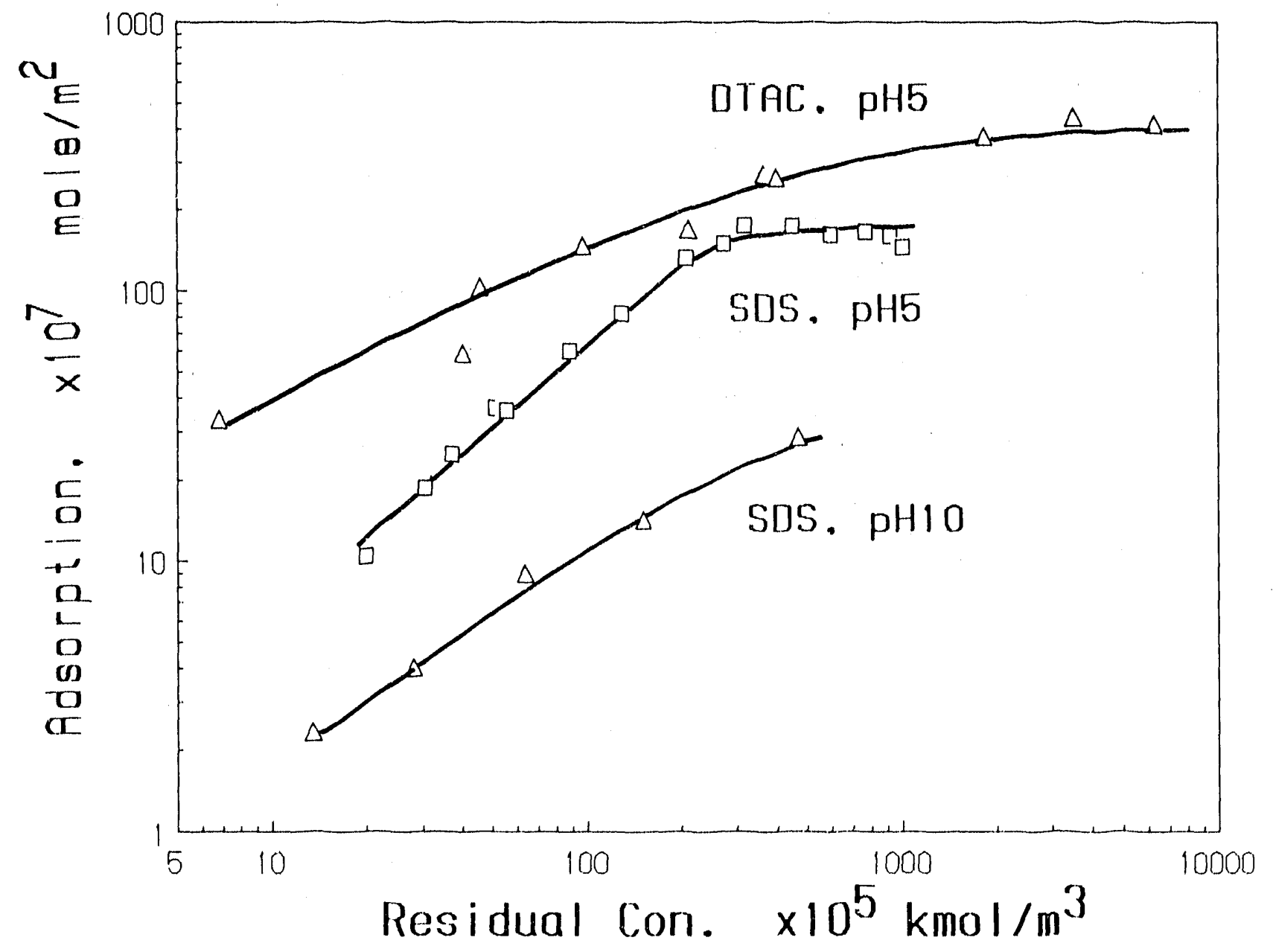

Figure 8 Adsorption of SDS and DTAC on kaolinite 


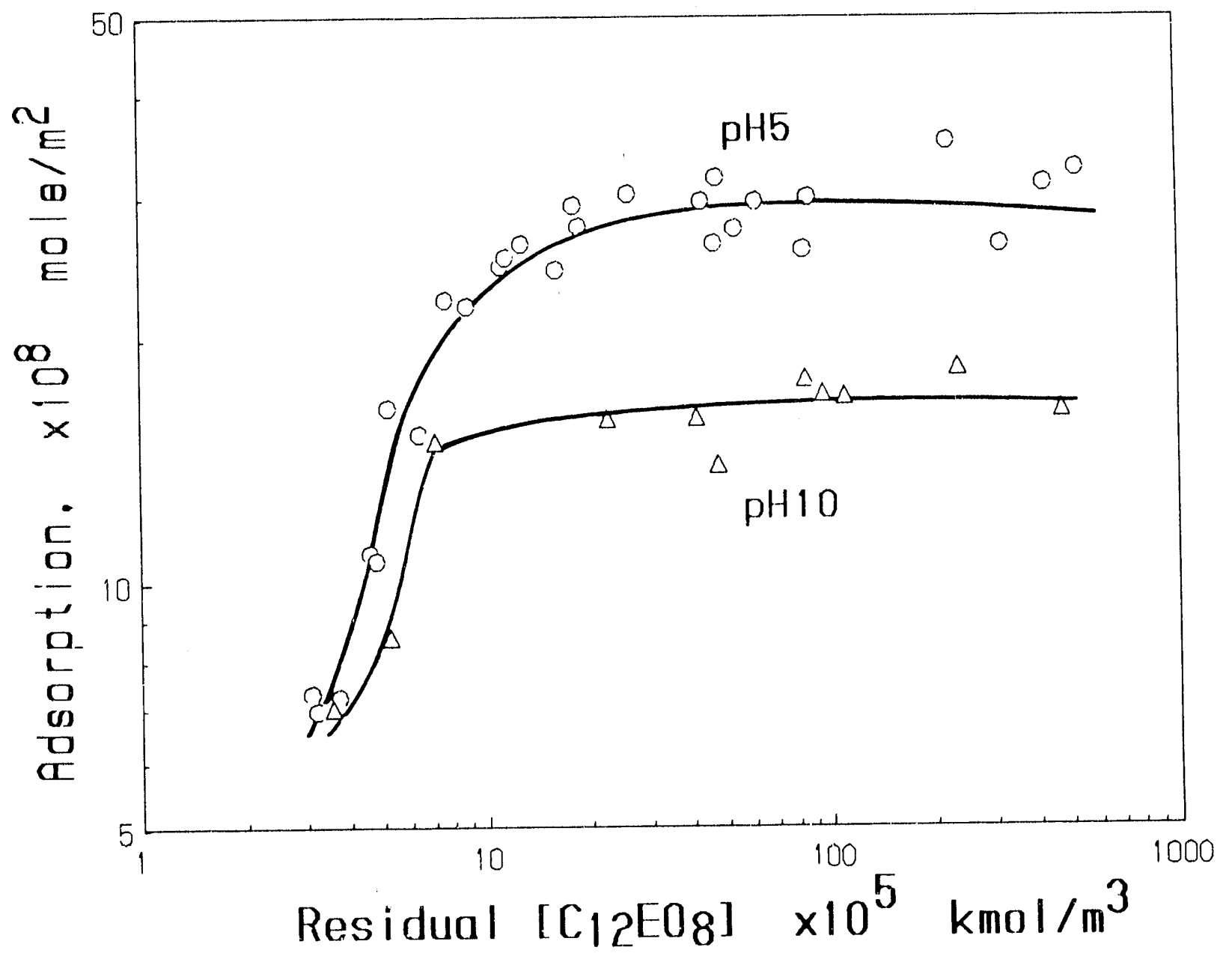

Figure 9 Adsorption of $\mathrm{C}_{12} \mathrm{EO}_{8} \mathrm{OH}$ on kaolinite 
the observed decrease in $\mathrm{C}_{12} \mathrm{SO}_{4} \mathrm{Na}$ adsorption as the pH is increased from 5 to 10 , since the number of positive sites on kaolinite does decrease with increasing pll $(15,22)$.

Further examination of the isotherms shows that the saturation adsorption density in the case of cationic $\mathrm{C}_{12}\left(\mathrm{CH}_{3}\right)_{3} \mathrm{NCl}$ is $4.35 \times 10-6 \mathrm{~mol} / \mathrm{m} 2$ which coincides with the monolayer capacity $(4.37 \times 10-6 \mathrm{~mol} / \mathrm{m} 2)$ calculated bascil on a crosssectional area of $38 \mathrm{~A}^{\circ}$ (23). This suggests that the cationic surfactant adsorbs not only on the negative sites but also covers the positive sites indicating the possibility of two dimencional condensation. Such a mechanism for cationic surfactant adsorption has also been suggested by Cases et al (24). In the case of anionic $\mathrm{C}_{12} \mathrm{SO}_{4} \mathrm{Na}$ the surface coverage at plateau, calculated based on a cross-sectional area of $53 \mathrm{~A}^{\circ}(23)$, is 56 percent which indicates that about half of the surface is covered by positive sites.

It has been reported by Cases et al (24) that the positive sites are present only on the broken edges and that even in most crystalline samples the broken edges constitute only 40 percent of the total surface area. Since the surface coverage anionic $\mathrm{C}_{12} \mathrm{SO}_{4} \mathrm{Na}$ is estimated to be above 50 pereent it appears that part of the surfactant adsorbs on negative sites through $\mathrm{Na}+$ counter ions (25) or positive sites are present also on the basal faces. The positive sites on basal faces can arise from the precipitation of dissolved aluminum hydroxide complexes.

It can be seen from figure 9 that the adsorption density of $\mathrm{C}_{12} \mathrm{EO} 8$, as in the case of $\left({ }_{12} \mathrm{SO}_{4} \mathrm{Na}\right.$, also decreases with an increase in $1 \mathrm{H}$. Similar decrease in adsorption with increase in pH has been reported for poly(ethylene) oxide (PLO) on silica (26). This similarity coupled with the fact that the ethylene oxide groups are the common hydrophilic moiety for hoth PEO and $\mathrm{C}_{12}$ EO would suggest a hydrogen bonding mechanism for $\mathrm{C}_{12} \mathrm{EO} \mathrm{O}_{8}$ adsorption as proposed for Pl:O (26) 
and nonionic TX-10() (27) adsorption on silica. Reduced adsorption at higher pll values can be attributed to the deprotonation of the surface hydroxyl groups $(28,29)$ which will result in a decrease in the number of hydrogen bonding sites available for $\mathrm{C}_{12} \mathrm{EO}_{8}$ adsorption. Using a molecular cross-sectional area of $6.5 \mathrm{~A}^{2}$ (2.3) for $\mathrm{C}_{12} \mathrm{EO}_{8}$ in the adsorbed state, the surface coverage at saturation can be calculated to be 11.7 percent which would also represent the percentage of the kaolinite surface covered by groups capable of hydrogen bonding with the nonionic surfactant.

An important inference that can be drawn from the adsorption studies discussed above is that, unlike alumina which barely adsorbs ethoxylated alcohols (30), and silica which adsorbs ethoxylated alcohol (30) but not $\mathrm{C}_{12} \mathrm{SO}_{4} \mathrm{Na}$, katolinite $\left[\left(\mathrm{Al}(\mathrm{OH})_{2}\right)_{2} \cdot \mathrm{O} \cdot\left(\mathrm{SiO}_{2}\right)_{2}\right]$, adsorbs both $\mathrm{C}_{12} \mathrm{SO}_{4} \mathrm{Na}$ and $\mathrm{C}_{12} \mathrm{EO}_{8}$ to about the same order of magnitude indicating that the kaolinite surface exhibits the characteristics of both alumina and silica with respect to the adsorption of these surfactants.

\section{Adsorption of surfactant mixtures}

The effect of mixing the ionic (anionic and cationic) and nonionic surfactants on the adsorption behavior of individual components is shown in figures 10-14. The isotherms in these figures have been divided in two regions below and above mixed CMCs of the solution, in order to facilitate explanation of the results.

Anionic - Nonionic Surfactants System:

Adsorption isotherms: pre-plateau region: The isotherms for the adsorption of sodium dodecylsulfate $\left(\mathrm{C}_{12} \mathrm{SO}_{4} \mathrm{Na}\right)$ from mixtures of different composition are shown in figure 10 , while those of $\mathrm{C}_{12} \mathrm{EO}_{8}$ are plotted in figure 11 . It can be seen from figure 10 that the affinity of $\mathrm{C}_{12} \mathrm{SO}_{4} \mathrm{Na}$ to the surface is enthanced by the presence of $\mathrm{C}_{12} \mathrm{EO}_{8}$ as indicated by the continuous shift of $\mathrm{C}_{12} \mathrm{SO}_{4} \mathrm{Na}$ isotherms 


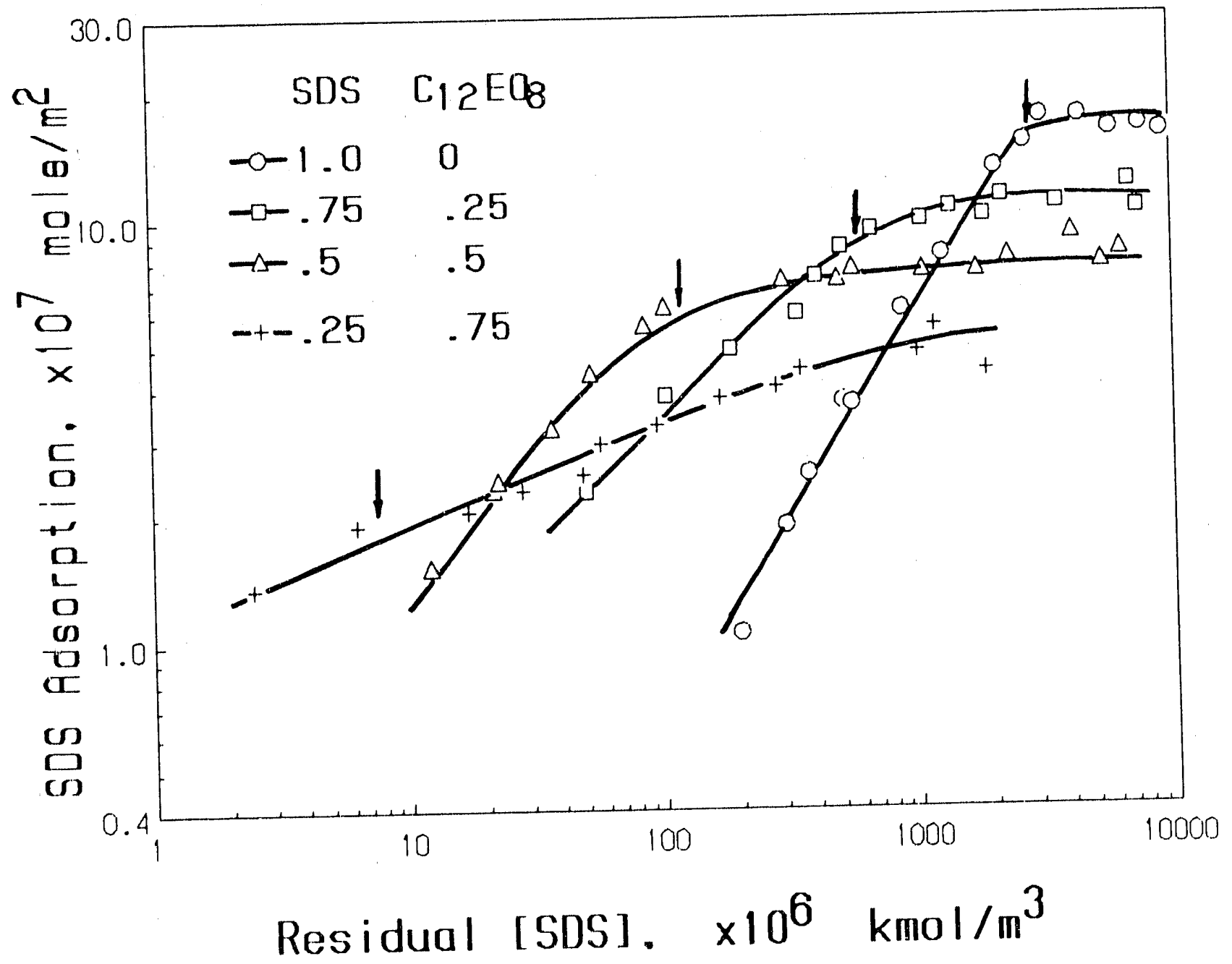

Figure 10 Adsorption of SDS on kaolinite from SDS $/ \mathrm{C}_{12} \mathrm{EO}_{8} \mathrm{OH}$ mixture 


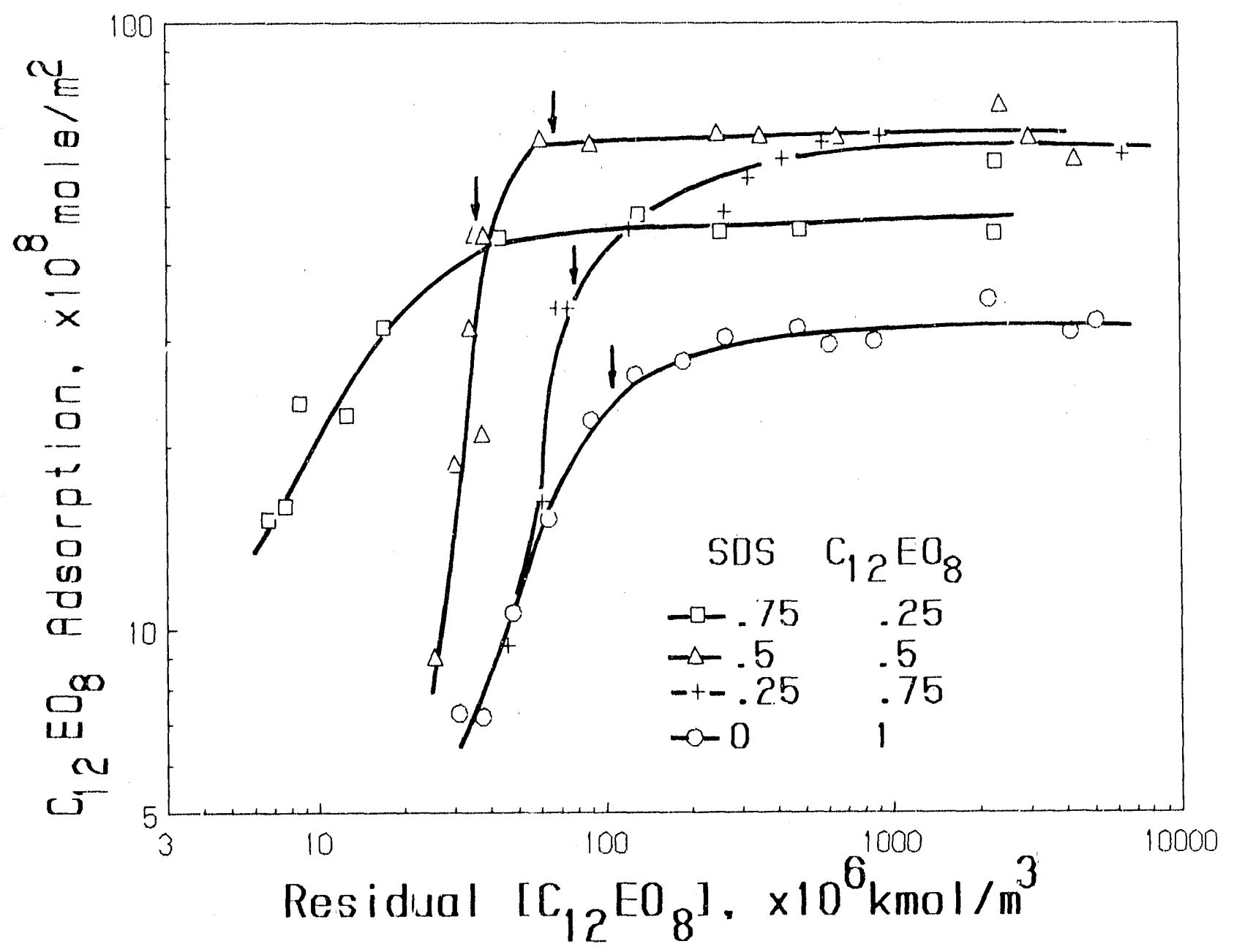

Figure 11 Adsorption of $\mathrm{C}_{12} \mathrm{EO}_{8} \mathrm{OH}$ on kaolinite from SDS $/ \mathrm{C}_{12} \mathrm{EO}_{8} \mathrm{OH}$ mixture 


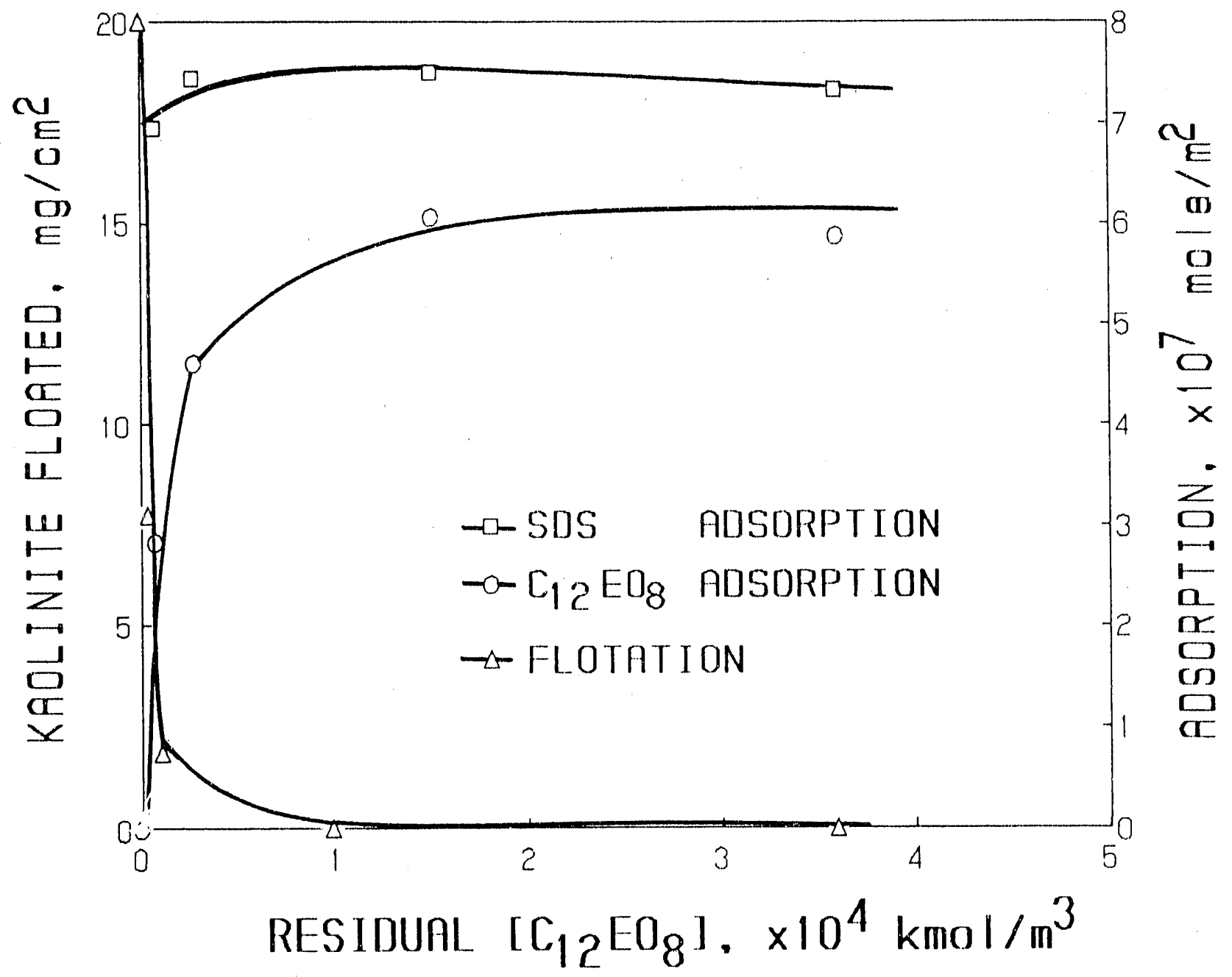

Figure 12 Skin flotation of kaolinite after mixed surfactant adsorption 


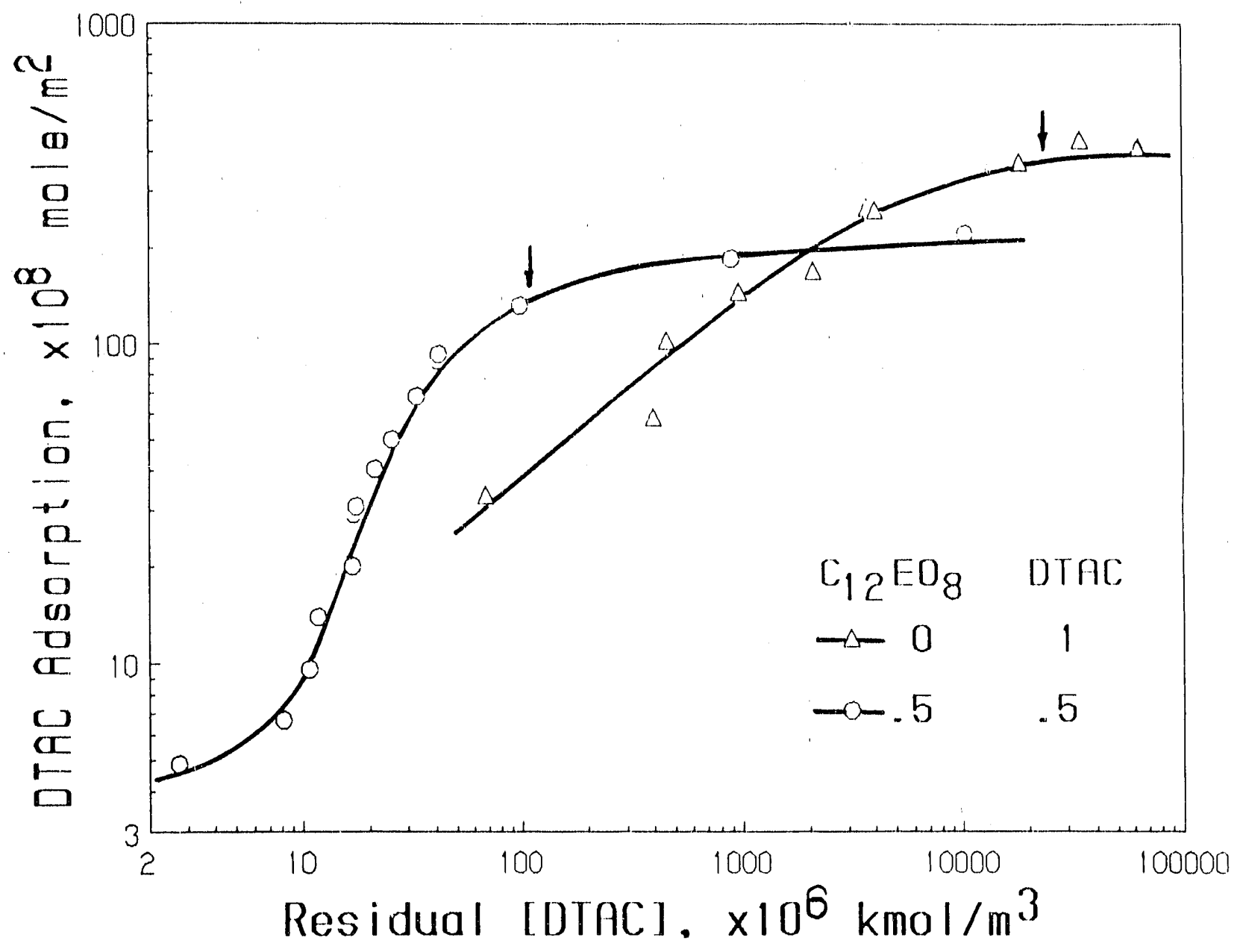

Figure 13 Adsorption of DTAC on kalolinite from DTAC/C 12 EO $\mathrm{EO}_{8} \mathrm{OH}$ mixtures 


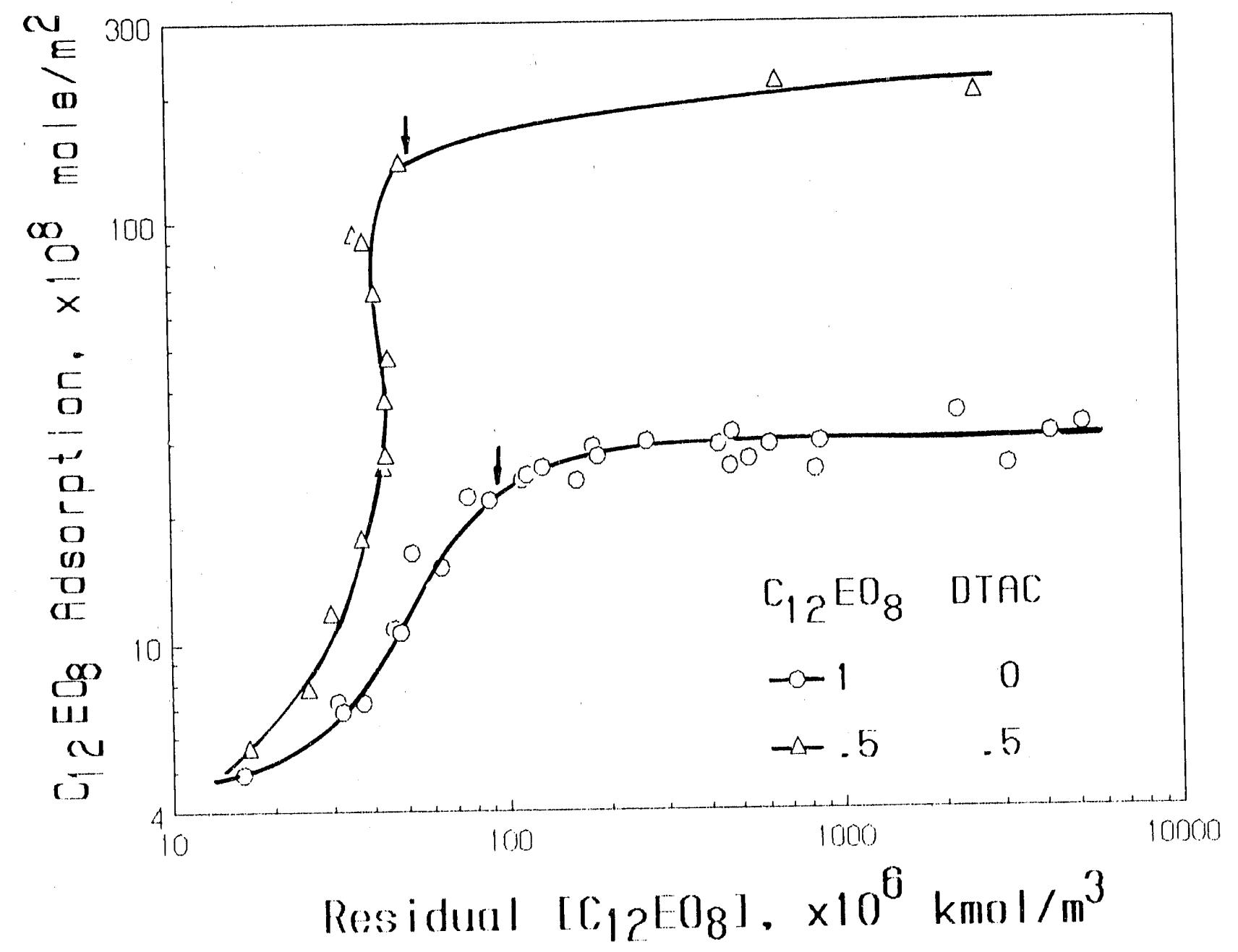

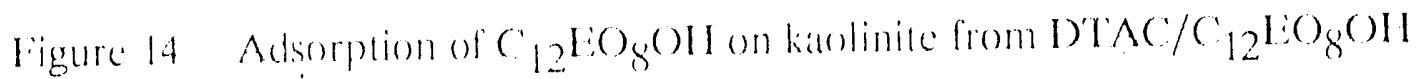
mixtures 
towards the left with increase of the molar ratio of $\mathrm{C}_{12} \mathrm{EO}_{8}$. This can be explained in terms of the co-adsorption of $\mathrm{C}_{12} \mathrm{SO}_{4} \mathrm{Na}$ and $\mathrm{C}_{12} \mathrm{EO}_{8}$ as shown schematically in figure 15; $\mathrm{C}_{12} \mathrm{SO}_{4} \mathrm{Na}$ adsorption is assisted, in addition to its electrostatic interaction with the positive sites on kaolinite, by the chain-chain interaction with $\mathrm{C}_{12} \mathrm{EO}_{8}$ adsorbed on adjacent sites. Because of the free energy gain from such chain-chain interactions the residual concentration, or the chemical potential, of $\mathrm{C}_{12} \mathrm{SO}_{4} \mathrm{Na}$ required to achieve a certain level of adsorption is reduced resulting in a shift of the isotherm towards the left.

Another feature to be noted on the $\mathrm{C}_{12} \mathrm{SO}_{4} \mathrm{Na}$ adsorption isotherm is the decrease in the slope of the isotherm as the molar ratio of ${ }_{{ }_{12}} \mathrm{EO}_{8}$ is increased. For adsorption of pure $\mathrm{C}_{12} \mathrm{SO}_{4} \mathrm{Na}$ on kaolinite, a slope of 1 is obtained on a logarithmic plot, indicating the absence of lateral chain-chain interactions (31). A value less than one for the slope, as seen in figure 10, suggests electrostatic hindrance for $\mathrm{C}_{12} \mathrm{SO}_{4} \mathrm{Na}$ adsorption resulting possibly from the masking of the positive sites by adsorbed ethylene oxide chains (figure 15b).

The adsorption of $\mathrm{C}_{12} \mathrm{EO}_{8}$, similar to that of $\mathrm{C}_{12} \mathrm{SO}_{4} \mathrm{Na}$, is enhanced by the presence of $\mathrm{C}_{12} \mathrm{SO}_{4} \mathrm{Na}$ as seen from a continuous shift in the isotherm to the left with increase in the molar ratio of $\mathrm{C}_{12} \mathrm{SO}_{4} \mathrm{Na}$. This can again be attributed to the chain-chain interaction between $\mathrm{C}_{12} \mathrm{SO}_{4} \mathrm{Na}$ and $\mathrm{C}_{12} \mathrm{EO}_{8}$. It is conceivable that due to chain-chain interaction hetween adsorbed $\mathrm{C}_{12} \mathrm{SO}_{4} \mathrm{Na}$ and $\mathrm{C}_{12} \mathrm{EO}_{8}$, mixed surfactant clusters will be formed at the interface. These mixed surfactant clusters, serving as hydrophobic pools, can enhance the adsorption of $\mathrm{C}_{12} \mathrm{EO}_{8}$ by abstracting the hydrocarbon chains of the highly surface active non-ionic surfactant into the clusters leaving the ethylene oxide segments protruding into the bulk solution, as shown schematically in figure $1.5 \mathrm{c}$. 


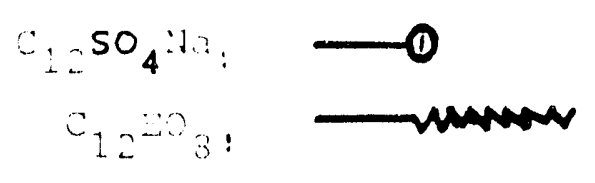

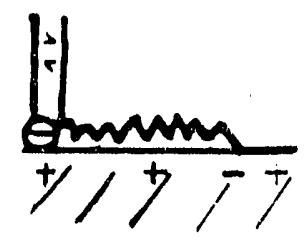

(a)

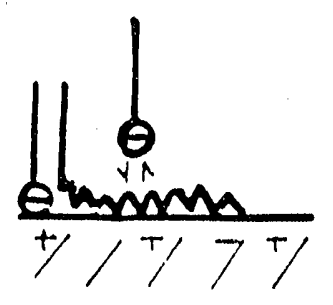

(i)

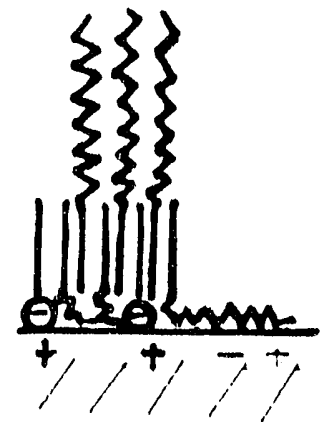

(i)

Figure 15 Schematic representaltion of surfactant mixture adsorption on kabolinite 
Adsorption isotherms - platealu region: Il can be seen from figure I0 than in platcint region (above $\mathrm{CMC}$ ) the adsorption of $\mathrm{C}_{12} \mathrm{SO}_{4} \mathrm{Na}$ while alone reaches a platteitl, whercas in the presence of $\mathrm{C}_{12} \mathrm{EO}_{8}$ continues to increase even above ( $\mathrm{NAC}$. This is because in mixed surfactant systems, unlike in single surfactant solutions, the monomer concentration of anionic surfactant does increase above CMC, while that of nonionic surfactant does decrease (30,32). A consistent decrease of $\mathrm{C}_{12} \mathrm{SO}_{4} \mathrm{Na}$ adsorption in plateau region is observed as the molar ratio of $\mathrm{C}_{12} \mathrm{EO} \mathrm{O}_{8}$ in the mixture is increased. This can be attributed to a) reduced $\mathrm{C}_{12} \mathrm{SO}_{4} \mathrm{Na}$ monomer concentration due to mixed micellization with $\mathrm{C}_{12} \mathrm{EO}_{8}$ as indicated by the decrease in $\mathrm{CMC}$ with increase in the molar ratio of $\mathrm{C}_{12} \mathrm{EO}_{8}$ and $\mathrm{b}$ ) masking of the positive sites that are responsible for $\mathrm{C}_{12} \mathrm{SO}_{4} \mathrm{Na}$ adsorption by the ethylence oxide chains of the adsorbed $\mathrm{C}_{12} \mathrm{EO}_{8}$.

In the case of the nonionic surfactant, since the monomer concentration does decrease with increase in the total surfactant concentration $(27,30)$, the isotherm of $\mathrm{C}_{12} \mathrm{EO}_{8}$ will be expected to pass through a maximum at the $\mathrm{CMC}$ of mixed surfactants. However, it can be seen from figure 12 that $\mathrm{C}_{12} \mathrm{EO}_{8}$ adsorption isotherms in plateau region are either flat or have a positive slope. This is attributed to the increased affinity of $\mathrm{C}_{12} \mathrm{EO}_{8}$ towards the surface modified by the adsorbed $\mathrm{C}_{12} \mathrm{SO}_{4} \mathrm{Na}$. As can be seen from figure 10, the adsorption of $\mathrm{C}_{12} \mathrm{SO}_{4} \mathrm{Na}$ increases even above mixed CMC. The effect of such continued modification of the interface by $\mathrm{C}_{12} \mathrm{SO}_{4} \mathrm{Na}$ adsorption apparently outweighs the effect of decrease in $\mathrm{C}_{12} \mathrm{EO}_{8}$ monomer concentration. It is also seen from figure 11 that the plateau adsorption density value of $\mathrm{C}_{12} \mathrm{EO}_{8}$ is, in all cases, enhanced by the presence of $\mathrm{C}_{12} \mathrm{SO}_{4} \mathrm{Na}$. Such an enhancement can be accounted for, as explained carlier, by the abstraction of additional $\mathrm{C}_{12} \mathrm{EO}_{8}$ chains into the mixed surfactant clusters at the interface (see figure 15c). Such hydrocarbon chain abstraction is apparently highly dependent on the organization of the mixed surfactant clusters at the 
interface and therefore maximum adsorption increase occurs at a certain molar ratio between the two surfactants. As is seen in figure 11, the maximum $\mathrm{C}_{12} \mathrm{EO}_{8}$ adsorption in plateau region occurs at about 1:1 molar ratio between $\mathrm{C}_{12} \mathrm{SO}_{4} \mathrm{Na}$ and $\mathrm{C}_{12} \mathrm{EO}_{8}$. The dependence of $\mathrm{C}_{12} \mathrm{EO}_{8}$ hydrocarbon chain abstraction on the organization of mixed surfactant clusters is also revealed by the change in slope of the $\mathrm{C}_{12} \mathrm{EO}_{8}$ isotherms in pre-plateau region. As seen in figure 11, the slope of the adsorption isotherm increases in the presence of $\mathrm{C}_{12} \mathrm{SO}_{4} \mathrm{Na}$ with the maximum slope occurring around 1:1 molar ratio, indicating a more compact arrangement of the adsorbed surfactants in the cluster, which eventually leads to maximum $\mathrm{C}_{12} \mathrm{EO}_{8}$ abstraction as shown by the highest plateau adsorption density value at this ratio.

The theory of abstraction of hydrocarbon chain of $\mathrm{C}_{12} \mathrm{EO}_{8}$ into the hydrophobic pool formed by the clusters of mixed surfactant is also supported by the (skin) flotation results. Since such an abstraction would result in orientation of ethylene oxide chains towards the bulk, the floatability of kaolinite decreases as the adsorption of $\mathrm{C}_{12} \mathrm{EO}_{8}$ is increased in the presence of $\mathrm{C}_{12} \mathrm{SO}_{4} \mathrm{Na}$ (figure 12).

Cationic - Nonionic Surfactants System:

Adsorption tests for this system was carried out at $1: 1$ molar ratio of the two surfactants. It can be seen from figures 13 and 14 that the isotherms obtained for the adsorption of cationic $\mathrm{C}_{12}\left(\mathrm{CH}_{3}\right)_{3} \mathrm{NCl}$ and nonionic $\mathrm{C}_{12} \mathrm{EO}_{8}$ exhibit features similar to that found for $\mathrm{C}_{12} \mathrm{SO}_{4} \mathrm{Na}_{1}-\mathrm{C}_{12} \mathrm{EO}_{8}$ system indicating that the adsorption mechanism is the same for both systems. 


\section{CONCLUSIONS}

It is evident that small alterations in surfactant structure such as change in the position of functional groups markedly affect the adsorption characteristics. The position of the sulfonate seems to be more important than that of the methyl groups as seen from the similar adsorption behavior of 135MXS and 125PXS as compared to that of $124 \mathrm{MXS}$. The main reason for the lower adsorption of $124 \mathrm{MXS}$ is the higher steric hindrance to the packing of the molecules in the hemimicelles. Calorimetric studies show that at low adsorption densities enthalpy is the driving force, while at higher concentrations, adsorption is entropy driven. The higher entropy of 135MXS and 125PXS above hemimicellization is due to greater release of structured water molecules upon hydrocarbon association arising from tighter packing of the molecules in the aggregate. The tighter packing indicates lesser steric hindrance to the aggregation of 135MXS and 125PXS species. Electrokinetic studies show that the charge characteristics of the three surfactants are the same. The mixed micellization of 124MXS and 135MXS surprisingly shows negative deviation from ideal behavior and regular solution theory fits the mixed CMC data well. Microcalorimetry was used to verify the validity of the thermodynamic assumptions of regular solution theory as applied to this system.

Synergistic interaction between surfactants was observed during the adsorption on kaolinite for both anionic-nonionic and cationic-nonionic surfactant mixtures. In these binary surfactant systems, affinity of the ionic and the nonionic surfactant towards the surface was found to be enhanced by the presence of one another in the pre-CMC region. Increased chain-chain interaction and the formation of mixed surfactant clusters have been proposed to be the main reasons for the observed synergism. Above CMC, dodecyl sulfate adsorption decreased with increasing ethoxylated alcohol composition and this was attributed to the decrease in dodecyl

sulfate monomer because of the decrease in CMC for the mixed surfactants. The 
abstraction of the hydrocarbon chains of ethoxylated alcohol into the hydrophoibic pools formed by mixed surfactant clusters is proposed to be responsible for the observed adsorption increase above mixed CMC. Hydrophobicity of the particle was low under such conditions presumably due to the orientation of the ethylene oxide chains in the bulk solution. Such abstraction is apparently dependent on the organization of the surfactants in the cluster and is therefore dependent on the composition of the surfactant mixtures with the maximum ethoxylated alcohol abstraction occurring at the equimolar ratio of the surfactants. Similarities observed between the anionic-nonionic and the cationic-nonionic surfactant mixtures suggest that the synergism observed in mixed surfactant system is mainly due to hydrophobic interactions between the hydrocarbon chains of the ionic and the nonionic surfactants.

\section{REFERENCES}

1. Somasundaran, P., Middleton, R. and Viswanathan, K.V., in Structure/Performance Relationship in Surfactants, pp. 270-290, M.J. Rosen ed., ACS Symp. Ser., 253, (1984).

2. van Os, N.M., Danne, G.J. and Bolsman, T.A.B.M., J. Coll. Interf. Sci., 115, 402, (1987).

3. van Os, N.M., Danne, G.J. and Bolsman, T.A.B.M., J. Coll. Interf. Sci., 123, 267, (1988).

4. Rosen, M.J., Zhu, Z.H., Gu, B. and Murphy, D.S., Langmuir, 4, 1273, (1988).

5. Somasundaran, P., Adsorption from Flooding Solutions in Porous Media, Annual Report Submitted to DOE, NSF and a Consortium of Supporting Industrial Organizations, Columbia University, New York, 1987.

6. Rosen, M.J. and Hua, X.Y., J. Coll. Interf. Sci., 86, 164 (1982).

7. Holland, P.M., in Phenomena in Mixed Surfactant Systems, J.F. Scamehorn, ed., ACS Symp. Ser., 311, 102, (1986).

8. Scamehorn, J.F., Schechter, R.S. and Wade, W.H., J. Disp. Sci. Tech., 3, 261 (1982). 
9. Osborne-Lee, I.W., Schechter, R.S., Wade, W.H and Barakat, Y., J. Coll. Interf. Sci., 108, 60 (1985).

10. Holland, P.M. and Rubingh, D.N., J. Phys. Chem., 87, 1984 (1983).

11. Mysels, K.J. and Otter, R.J., J. Coll. Interf. Sci., 16, 462, (1961).

12. Hall, D.G. and Huddleston, R.W., Coll. and Surf., 13, 209, (1985).

13. Osborne-Lee, I.W., Schechter, R.S. and Wade, W.H., J. Coll. Interf. Sci., 94, 179 (1983).

14. Harwell, J.H., Roberts, B.L. and Scamehorn, J.F., Coll. and Surf., 32, 1, (1988).

15. Siracusa, P.A. and Somasundaran, P., J. Coll. Interf. Sci., 114, 184 (1986).

16. Li, Z. and Rosen, M.J., Anal. Chem., 53, 1516 (1981).

17. J. Phys. Chem. Ref. Data, Vol. 11, Suppl. 2, (1982).

18. Barry, B.W. and Russell, G.F.J., J. Coll. Interf. Sci., 40, 174, (1972).

19. Drost-Hansen, W., Structure of Water Near Solid Interfaces, in Chemistry and Physics of Interfaces-II, American Chemical Society Publications, Washington, D.C., (1971).

20. Holland, P.M., in Structure and Performance Relationships in Surfactants, M.J. Rosen, ed., ACS Symp. Ser., 253, 141 (1984).

21. Rathman, J.F. and Scamehorn, J.F., Langmuir, 4, 474, (1988).

22. William D.J.A. and Williams, K.P., J. Coll. Interf. Sci. 65, 79, (1978).

23. Rosen, M.J., Surfactants and Interfacial Phenomena, John Wiley \& Sons, New York, (1989), p.70

24. Cases, J.M., Cunin, P., Grillet, Y., Poinsingnon, C., Yvon, J., Clay Minerals, $21,51,(1986)$.

25. Poirier, J. E., Cases, J.M.,in Solid-Liquid Interaction in Porous Media, Ed. Technip, Paris, (1985), p.429.

26. J. Rubio and J.A. Kitchener, J. Coll. Interf. Sci., 57, 132, (1976).

27. Partyka, S., Zaini, S., Lindheimer, M. and Brun, B., Coll. and Surf., 12, 255, (1984).

28. Ahmed, S. M. Canadian J. Chem. 44, 1663, (1966).

29. Yates, D.E., Levine S., and Healy, T. W., J. C. S. Faraday Trans I, 70, 1807, $(19 / 4)$. 
30. Edward Fu, Ph.D. Thesis, Columbia University, New York, 1987.

31. P. Somasundaran and D.W. Fuerstenau, J. Phys. Chem. 70), 90, (1966).

32. D.N. Rubing, in K.L. Mittal, ed. "Solution Chemistry of Surfactants" Plenum Press, New York, (1978), 1, p.337. 

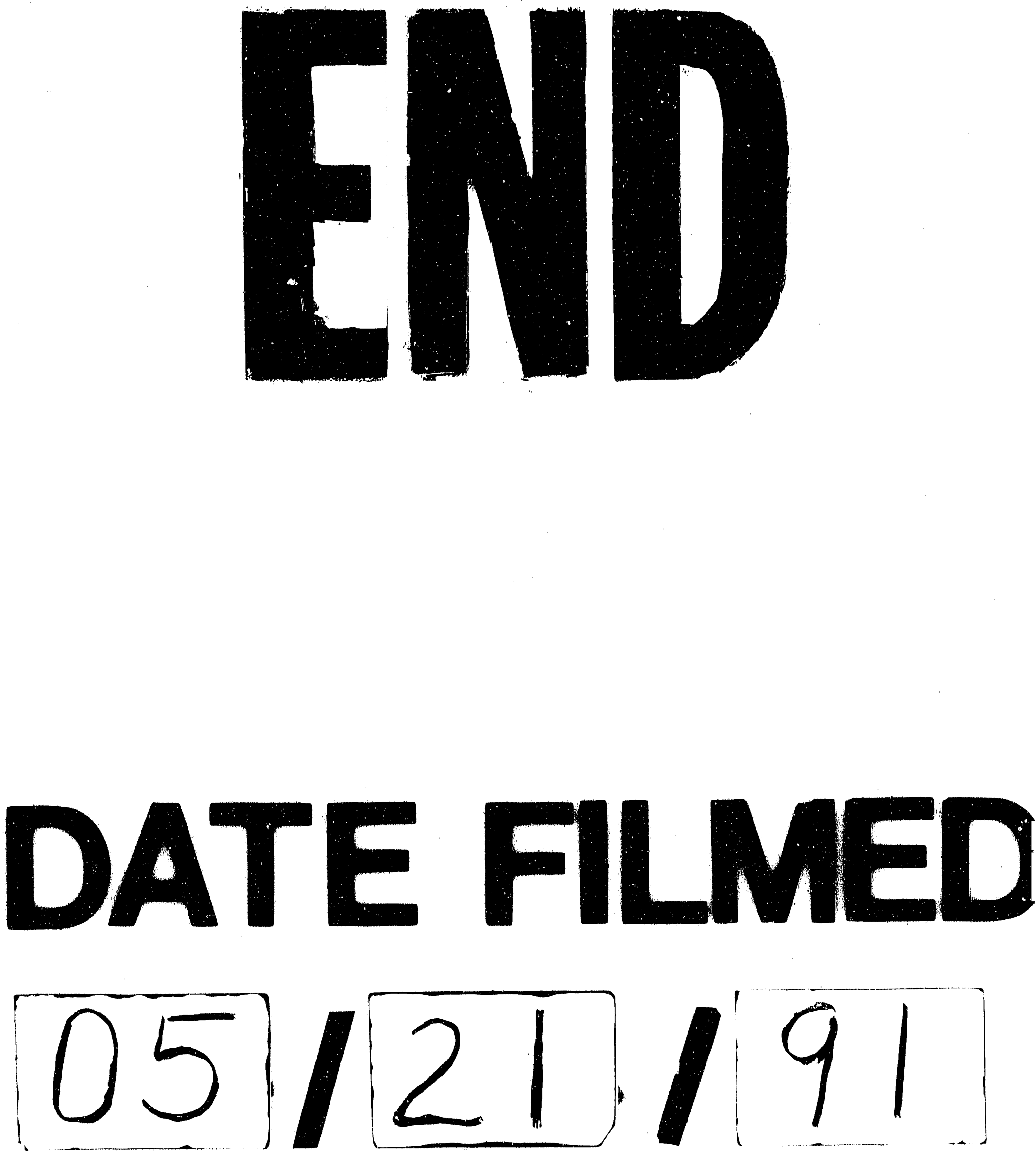
